NBER WORKING PAPER SERIES

\title{
POLLUTION AND LABOR MARKET SEARCH EXTERNALITIES OVER THE BUSINESS CYCLE
}

\author{
John Gibson \\ Garth Heutel \\ Working Paper 27445 \\ http://www.nber.org/papers/w27445 \\ NATIONAL BUREAU OF ECONOMIC RESEARCH \\ 1050 Massachusetts Avenue \\ Cambridge, MA 02138 \\ June 2020
}

Thanks to Yin Germaschewski, Marc Hafstead, Jay Harvoth, Milton Marquis, and seminar participants at the ASSA, Econometric Society, AERE, Midwest Macro, and SEA conferences for comments, and to Ken Castellanos and Wenwen Li for valuable research assistance. The views expressed herein are those of the authors and do not necessarily reflect the views of the National Bureau of Economic Research.

NBER working papers are circulated for discussion and comment purposes. They have not been peer-reviewed or been subject to the review by the NBER Board of Directors that accompanies official NBER publications.

(C) 2020 by John Gibson and Garth Heutel. All rights reserved. Short sections of text, not to exceed two paragraphs, may be quoted without explicit permission provided that full credit, including $(\odot$ notice, is given to the source. 
Pollution and Labor Market Search Externalities Over the Business Cycle

John Gibson and Garth Heutel

NBER Working Paper No. 27445

June 2020

JEL No. E24,E32,Q58

\title{
ABSTRACT
}

We study the relationship between unemployment, environmental policy, and business cycles. We develop a dynamic stochastic general equilibrium real business cycle model that includes both a pollution externality and congestion externalities from labor market search frictions, which generate unemployment. We consider two policies to address the market failures: an emissions tax and a tax or subsidy on job creation. With both policies present, the efficient outcome can be achieved. When one policy is constrained or absent, we solve for the second best. The absence of a vacancy policy to address the congestion externalities substantially affects the value of the emissions tax, both in steady state and over the business cycle.

\author{
John Gibson \\ COBA Office 226 \\ University of Texas at El Paso \\ El Paso, TX 79902 \\ USA \\ jdgibson@utep.edu \\ Garth Heutel \\ 436 Andrew Young School \\ Department of Economics \\ Georgia State University \\ PO Box 3992 \\ Atlanta, GA 30302-3992 \\ and NBER \\ gheutel@gsu.edu
}




\section{Introduction}

The effects of environmental policy on unemployment are at the center of the public debate on environmental policy - many argue that these policies are "job-killing regulations." Since the Great Recession, the importance of business cycles has come to the forefront, highlighting the impact of cycles on unemployment and the environment. Standard neoclassical economic theory dictates that the inefficiencies caused by externalities can be eliminated through Pigouvian pricing, e.g. pollution taxes. Search-and-matching theories of unemployment involve externalities too, where both workers looking for jobs and employers looking to hire create congestion in the labor market. The interaction between multiple market failures the congestion externalities from labor market search and the production externalities from pollution - can have important policy implications. The efficient Pigouvian response to a negative pollution externality may change when labor market congestion externalities are present. Furthermore, the efficient level of these policies may vary over the business cycle.

The purpose of this paper is to study the efficiency effects of policy in an economy with unemployment, pollution, and business cycles. We begin with an analytical model of policy in the presence of pollution externalities and labor market search frictions. We then develop a dynamic stochastic general equilibrium (DSGE) model where fluctuations are driven by productivity shocks, as in the real business cycle (RBC) model. We add two features to the standard RBC model: a pollution externality and labor market search frictions that create unemployment. We allow for two policy options: an emissions tax and a tax or subsidy on job vacancy creation. We calibrate the model to the U.S. economy and carbon dioxide emissions and numerically solve it. We simulate both the first-best policy responses, where the government dynamically optimizes both policy tools, and second-best policies, where one policy is constrained.

A growing literature incorporates environmental policy in RBC models by modeling pol- 
lution as a byproduct of production that negatively affects productivity $\bigsqcup^{1}$ While labor is included as an input in most of these models, none include labor market search frictions or involuntary unemployment. A second literature incorporates involuntary unemployment via Diamond-Mortensen-Pissarides (DMP) labor market search frictions into RBC models. ${ }^{2}$ 3 This literature does not consider pollution or pollution policy. A third literature studies the unemployment effects of environmental policy using DMP labor market search frictions, though without RBC fluctuations. $4^{4}$ Our model combines all three of these literatures. Our RBC model merges the pollution-generating production process of Heutel $(2012)$ with the DMP search model of Atolia et al. (2018), thus adding cyclical fluctuations to a pollution and labor market search model like Aubert and Chiroleu-Assouline (2019).

Fewer papers consider the policy implications of the externalities generated by the DMP search model. Shi and Wen (1999) and Lu (2019) both consider various policies in addressing these externalities, including the minimum wage, unemployment insurance, and vacancy subsidies. In our paper, we focus on vacancy taxes or subsidies. Shi and Wen (1999) find that this is the most efficient policy, and we also find that this policy can bring about the first best. We consider dynamically-optimal policies, where the policies can vary with the business cycle; this is modeled in neither Shi and Wen (1999) nor Lu (2019) $!^{5}$ An enormous literature studies optimal environmental policy, and some of that literature considers the interactions between pollution externalities and other market failures. For example, Jaffe et al. (2005) model the

\footnotetext{
${ }^{1}$ For example, Fischer and Springborn (2011), Heutel (2012), Annicchiarico and Di Dio (2015), and Dissou and Karnizova (2016). See Fischer and Heutel (2013) for a literature review.

${ }^{2}$ This literature dates back to Andolfatto (1996) and Merz (1995), though we follow the more recent works of Atolia et al. (2018) and Atolia et al. (2019) and adapt a calibration strategy similar to Hagedorn and Manovskii (2008).

${ }^{3}$ For a discussion of the basic DMP search and matching model, see Diamond (1982), Pissarides et al. (1985), Mortensen and Pissarides (1994), and Pissarides (2000). Rogerson et al. (2005) provides a literature review.

${ }^{4}$ Hafstead and Williams (2018) and Aubert and Chiroleu-Assouline $(2019)$ do so in analytical general equilibrium models, and Hafstead et al. (2018) does so in a computable general equilibrium model.

5 Blanchard and Galí (2010) consider a New Keynesian DMP model that includes monetary policy tools, which we do not include.
} 
interaction between pollution externalities and innovation externalities, and Kennedy (1994) models the interaction between pollution externalities and market power. We know of no other paper that considers the policy implications of the interaction between a pollution externality and congestion externalities arising from labor market search frictions..$^{6}$

Our analytical model provides intuitions on the relationship between these multiple market failures and efficient Pigouvian pricing, which aids the interpretation of the simulation results from our numerical model. The pollution externality is a standard negative externality, internalized by a Pigouvian tax on the source of the externality (in the model, production). Labor search creates two offsetting congestion externalities. Each unemployed worker searching for employment reduces the probability of a match for all other unemployed workers but increases the probability of a match for all hiring firms. Each firm posting a job vacancy reduces the probability of a match for all other hiring firms but increases the probability of a match for all unemployed workers. Neither the worker nor the firm considers its impact on others' matching probabilities. The congestion externality caused by the unemployed worker leads to an inefficiently low level of employment, and the congestion externality caused by the hiring firm leads to an inefficiently high level of employment.

These two congestion externalities perfectly offset each other under a certain condition, the well-known "Hosios condition" (Hosios, 1990). If this condition is not met, then the inefficiency from the congestion externalities can be eliminated through a Pigouvian price on hiring. The efficient price instrument is either a subsidy to hiring or a tax on hiring, depending on whether equilibrium employment is inefficiently high or inefficiently low. We present closed-form expressions for the pair of policy instruments (production tax and hiring tax or subsidy) that induces efficiency. We also demonstrate the interaction between the two sets of externalities and the two policy instruments. For example, the magnitude of

\footnotetext{
${ }^{6}$ Both Hafstead and Williams (2018) and Aubert and Chiroleu-Assouline (2019) model DMP search frictions and environmental policy, but neither solves for optimal policy à la Pigou or Ramsey.
} 
the pollution externality affects the level of the hiring tax or subsidy (which targets the congestion externalities).

Our calibrated DSGE model finds that the unregulated decentralized equilibrium has higher pollution and higher employment than the efficient outcome. Employment is higher in the decentralized equilibrium because the calibrated parameters in the wage-setting mechanism favor firms, resulting in a greater congestion externality from the firms than from the workers. Unemployment in the decentralized equilibrium is too low relative to the efficient outcome, and thus a tax on vacancy creation (rather than a subsidy to it) increases efficiency. This direction of the inefficiency (too little unemployment rather than too much) depends on the values of the two parameters crucial to the Hosios condition - the wage bargaining parameter and the matching function elasticity - which we demonstrate in sensitivity analysis. Unemployment is too low only on grounds of efficiency, not equity, and we show that moving to the efficient outcome disproportionately burdens workers relative to firms.

When both policy instruments - a vacancy tax and an emissions tax - are present, the efficient outcome can be achieved. When one of the taxes is unavailable, we solve for the second-best value of the remaining tax, which must be adjusted to "pick up the slack" and address both sets of externalities. Most importantly, when the vacancy tax is unavailable, the second-best level of the emissions tax is 33 times greater than its first-best value at steady state. Furthermore, the cyclical properties of the two taxes differ, with the secondbest emissions tax only half as volatile as the first-best emissions tax. Given that vacancy taxes are rarely if ever implemented, these results point to a potentially enormous policy implication for the design of emissions taxes.

The paper proceeds as follows. In Section 2, we present a simple analytical model in which we do not consider business cycles but show through analysis of the steady-state equilibrium the main intuitive findings. Then in Section 3 we present the full DSGE model. In Section 4 we provide a discussion of our calibration strategy. In Section 5 we present our 
results, and in Section 6 we conclude.

\section{Analytical Model}

In this section, we present steady-state results and policy responses for the canonical DMP

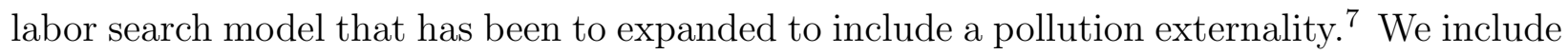
two possible policy instruments: a hiring tax or subsidy to internalize the search congestion externalities and a production tax or subsidy to internalize the pollution externality. In this section, we briefly describe the results and the intuitions; details and derivations are relegated to the appendix section $\mathrm{A}$.

The economy consists of a continuum of homogeneous firms and a continuum of homogeneous workers. Time is continuous, and the size of the labor force is fixed at $L$. The unemployment rate, or the fraction of workers who are unemployed, is $u$. The vacancy rate, or the ratio of job vacancy postings to the total labor force, is $v$. Define labor market tightness $\Phi \equiv v / u$. The number of job matches $m$ in a time period is a function of labor market tightness. The vacancy-filling rate, or the probability of a given job vacancy being filled, is defined as $m / v=q(\Phi)$. Let $q^{\prime}(\Phi) \leq 0$, so that a higher labor market tightness (higher ratio of job vacancies to unemployed workers) leads to a lower probability of a vacancy being filled. Let the elasticity of $q$ be between -1 and 0 and its absolute value be $\eta(\Phi)$ (i.e. $\left.\eta(\Phi) \equiv-\frac{\Phi q^{\prime}(\Phi)}{q(\Phi)}\right)$. The value of $\eta(\Phi)$ is thus the negative of the elasticity of the vacancy-filling rate with respect to labor market tightness. The job-finding rate, or the probability of a given unemployed worker finding a job is $m / u=f(\Phi)=\Phi q(\Phi)$, which is increasing in $\Phi$, so that a higher labor market tightness leads to a higher probability of a worker finding a job. All workers and firms treat the labor market tightness variable $\Phi$ as exogenous.

Each period an exogenous fraction of jobs, $s$, is destroyed (Shimer, 2005). In a given

\footnotetext{
${ }^{7}$ Specifically, we combine a pollution externality with the basic model of sections 1.1-1.5 of Pissarides (2000), the efficiency analysis of section 8.1 and the introduction of policy instruments in section 9.1-9.3.
} 
small time interval $\delta t$, the number of workers who enter unemployment is $s(1-u) L \delta t$, and the number of workers who leave unemployment is $u \Phi q(\Phi) L \delta t$. Thus the change in the unemployment rate is $\dot{u}=s(1-u)-\Phi q(\Phi) u$, and the steady-state unemployment rate is

$$
u=\frac{s}{s+\Phi q(\Phi)}
$$

The value of a job's output is $p(1-d)$, where $p$ is the baseline exogenous productivity level, and $1-d$ represents a pollution externality. All workers and firms treat the externality as exogenous. The hiring cost is $p(1-d) c$, where $c$ is also exogenous. The discount rate is $r$, the workers' bargaining power (or their share of the match surplus) is $b$, and the return to unemployment (or the value of leisure) is $z .8$

There are two policy variables. First, firms receive a one-time hiring subsidy when a match is created. The value of the subsidy is proportional to net productivity and equals $H p(1-d)$, where $H$ is the policy variable. Second, firms receive an employment subsidy $a$ for each filled job. The distinction is that the hiring subsidy $H$ is a one-time payment, while the employment subsidy $a$ occurs each period the match is operational. Both the hiring and employment subsidies may be negative, in which case they are a tax rather than a subsidy.

In the appendix, we show how in the steady state, the model's equilibrium is characterized by three equations (equations 1, A.1, and A.2. . The core endogenous variables are the wage $w$, the unemployment rate $u$, and labor market tightness $\Phi$. The solution depends on the values of the policy parameters $H$ and $a$. To get an equation that will be more useful for policy analysis, substitute the wage from equation A.2 into equation A.1 to get

$$
(p(1-d)-z)(1-b)-\frac{s+r+b \Phi q(\Phi)}{q(\Phi)} p c(1-d)+(1-b)(r+s) p H(1-d)+(1-b) a=0 .
$$

\footnotetext{
${ }^{8}$ As in Pissarides (2000), we assume that productivity (here $p(1-d)$ ) is greater than or equal to the return to unemployment $z$, which ensures that the wage is greater than or equal to $z$, ensuring that workers stay in their jobs.
} 
Finally, consider the efficient allocation in this model, which in general will not coincide with the decentralized equilibrium because of the pollution and congestion externalities. The social planner maximizes a social welfare function that includes the value of output produced by the employed, the leisure value of the unemployed, and the cost of job search. Unlike the workers or the firms, the social planner recognizes that the pollution externality $d$ is not exogenous but rather a function of total production. In particular, it is a function of the unemployment rate, $d(u)$, where $d^{\prime}(u)<0$, indicating that higher employment (i.e. lower unemployment) leads to higher damages $d$. Also, unlike the workers or firms, the social planner recognizes the congestion externalities from labor search by treating labor market tightness $\Phi$ as endogenous rather than fixed.

The appendix shows that the solution to the planner's problem can be expressed as:

$$
(p(1-d(u))-z)(1-\eta(\Phi))+d^{\prime}(u) p((1-u)+c \Phi u)(1-\eta(\Phi))-\frac{s+r+\eta(\Phi) \Phi q(\Phi)}{q(\Phi)} p c(1-d(u))=0
$$

Equation 3 is the key equation describing the efficient levels of employment and vacancies.

We can now compare equation 2 , which describes the decentralized equilibrium, to equation 3, which describes the efficient allocation. Begin by making two simplifying assumptions. First, assume that $d^{\prime}(u)=0$, which is to say that the pollution "externality" $d$ is in fact not an externality but merely an exogenous shift in productivity. Second, assume that $\eta(\Phi)=b$, i.e. that the absolute value of the elasticity of the matching function equals the worker's bargaining power. This is the Hosios condition (Hosios, 1990). When both assumptions hold, equation 2 coincides with equation 3 without any policy intervention (i.e. the hiring and employment subsidies, $H$ and $a$, are both zero). The unregulated equilibrium is efficient.

The first assumption amounts to eliminating the pollution externality. The second assumption (the Hosios condition) amounts to setting the parameters such that the two opposing congestion externalities exactly offset each other. The intuition is explored in Hosios (1990) and Pissarides (2000, p. 185-187). Roughly, when the surplus is divided according to 
$b=\eta(\Phi)$, each side (workers and firms) is rewarded in accordance with its social contribution.

When either of these two assumptions is not met, then the unregulated equilibrium is not efficient. But, with policy instruments $H$ and $a$, the equilibrium can be made efficient. Dropping the two assumptions from the previous paragraphs, the equilibrium outcome is identical to the efficient outcome under the following two policy values:

$$
\begin{gathered}
H_{e f f}=(b-\eta(\Phi)) \frac{p(1-d(u))(1+c)-z}{(1-b)(r+s) p(1-d(u))} \\
a_{e f f}=d^{\prime}(u) p((1-u)+c \Phi u) \frac{1-\eta(\Phi)}{1-b}
\end{gathered}
$$

These two equations describe the values of the policy variables that induce the efficient levels of employment and vacancies. Both of them are Pigouvian prices, internalizing the externalities. It is clearest to see this in equation 5, where the employment subsidy is proportional to the marginal pollution externality $d^{\prime}(u)$. In fact, since $d^{\prime}(u)<0$, the efficient employment subsidy $a_{e f f}$ is negative, i.e. it is an employment tax. This Pigouvian tax internalizes the negative externality from each additional employed worker 9

The Pigouvian nature of the efficient hiring subsidy $H_{\text {eff }}$ is also evident. The efficient hiring subsidy has the same sign as $b-\eta(\Phi) .10$ If this expression is positive, then worker bargaining power is higher than the matching function elasticity, which leads to inefficiently high unemployment in the unregulated equilibrium. Thus, a hiring subsidy $\left(H_{e f f}>0\right)$ remedies the inefficiency. If $b-\eta(\Phi)$ is negative, so that the workers' bargaining power is lower than the matching function elasticity, then unemployment is inefficiently low in the unregulated equilibrium. Thus, a hiring tax $\left(H_{\text {eff }}<0\right)$ remedies the inefficiency.

Equations 4 and 5 also demonstrate the interaction between the two sets of externalities

\footnotetext{
${ }^{9}$ This analysis is similar to that done by Mortensen and Pissarides (2001) when solving for policy combinations that induce the first best; see their equations 30 and 31 and tables 2 and 3. But, they impose the Hosios condition and do not include a pollution externality, and so they are not addressing the same sources of market failure as we are.

${ }^{10}$ This relies on the assumption stated earlier that $p(1-d) \geq z$.
} 
and the two policies. The magnitude of the efficient hiring subsidy $H_{\text {eff }}$ depends on the level of the production externality $d(u)$. Specifically, the derivative of $H_{\text {eff }}$ with respect to $d(u)$ is the opposite sign as $b-\eta(\Phi)$ 11 Suppose $b-\eta(\Phi)>0$, implying that equilibrium unemployment is too high and the efficient hiring policy is a subsidy $\left(H_{\text {eff }}>0\right)$. All else equal, a higher level of the externality $d(u)$ implies a lower magnitude of the hiring subsidy (i.e. $\left.\frac{\partial H_{e f f}}{\partial d(u)}<0\right)$. This is intuitive - the higher externality means there is less justification for subsidizing hiring (which increases the externality).

From equation 5 , the efficient employment tax is scaled by $\frac{1-\eta(\Phi)}{1-b}$. When $b-\eta(\Phi)>0$, this fraction is greater than one. The inequality $b-\eta(\Phi)>0$ implies that the equilibrium level of unemployment is too high, and the efficient hiring policy $H_{\text {eff }}$ is a subsidy. Thus, when hiring is subsidized, the efficient employment tax $a_{\text {eff }}$ is greater than marginal external damages. The subsidy to hiring, which addresses the search congestion externality, exacerbates the pollution externality. So, the employment tax, which addresses the pollution externality, must increase to compensate.

The analytical model provides intuition about the relationship between the two sets of externalities and the policy responses 12 But it does so through several simplifying assumptions, like excluding capital, not explicitly modeling pollution or abatement, and not modeling productivity shocks. Furthermore, our analysis of this model concerns only the steady state and not any dynamic features. To address these other issues, we turn next to a DSGE model. The DSGE model will not provide closed-form analytical solutions like equations 4 and 5, so instead we will calibrate and numerically simulate the model.

\footnotetext{
$11 \frac{\partial H_{e f f}}{\partial d(u)}=\frac{-z(b-\eta(\Phi))}{(1-b)(r+s) p(1-d(u))^{2}}$

${ }^{12}$ In appendix section $\mathrm{A}$, we discuss how this model compares to other analytical models from the recent literature.
} 


\section{Numerical Model}

In this section, we build a dynamic stochastic general equilibrium (DSGE) model that incorporates both labor search frictions and a production process that generates harmful emissions into a real business cycle (RBC) model. Just as in the analytical model presented above, the search frictions and emissions result in a decentralized equilibrium with both congestion and pollution externalities. In the next two subsections, we detail the core elements of our model: the labor market and the production process. Then, in the following three subsections, we characterize the equilibrium behavior across the following three model environments: (i) the decentralized competitive equilibrium, (ii) the social planner's problem, and (iii) the Ramsey optimal dynamic equilibrium. We compare all model specifications to see how inefficiencies in the labor market impact model variables, with a specific focus on the level and cyclicality of the policy response.

\subsection{Labor Market}

Time is discrete, and the economy is populated by a representative household that contains employed and unemployed agents. Employed agents supply labor inelastically to the representative firm, while unemployed agents search for work. While our analytical model differs from our DSGE model in terms of timing, household structure, and the presence of a representative firm, many elements of the labor market are very similar across both models. The number of new employment matches $m_{t}$ formed in period $t$ is given by:

$$
m_{t}=\gamma_{1}\left(1-n_{t}\right)^{\gamma_{2}} v_{t}^{1-\gamma_{2}}
$$

where $v_{t}$ and $1-n_{t}$ denote vacancies and unemployment in time $t$, respectively. Given the matching function in equation 6, labor market tightness, $\Phi_{t}$, the vacancy-filling rate, $q_{t}$, and the job-finding rate, $f_{t}$, can be defined as in the analytical model. We also retain exogenous 
separations $s$ and the evolution of employment is:

$$
n_{t+1}=(1-s) n_{t}+m_{t}
$$

\subsection{Production and Pollution}

The representative firm produces potential output using the following production technology:

$$
y_{t}=\theta_{t} k_{t}^{\alpha} n_{t}^{1-\alpha}
$$

where $k_{t}$ and $n_{t}$ denote aggregate capital and employment, which are rented or hired from households, and $\theta_{t}$ is an exogenous total factor productivity shock, which follows:

$$
\ln \theta_{t+1}=\rho_{\theta} \ln \theta_{t}+\epsilon_{t+1}, \epsilon \sim N\left(0, \sigma_{\theta}\right)
$$

The total output produced in a given period, $Y_{t}$, depends positively on the level of potential output, $y_{t}$, and negatively on the stock of pollution present at the end of the period, $x_{t+1}$,

$$
Y_{t}=\left[1-d\left(x_{t+1}\right)\right] \cdot y_{t}
$$

where $d(\cdot)$ is a monotonically increasing damage function with values between 0 and 1 that measures the output loss from pollution. Producing output generates emissions, $e_{t}$ :

$$
e_{t}=\left(1-\mu_{t}\right) \cdot h\left(Y_{t}\right)
$$


where $h(\cdot)$ determines the relationship between output and unabated emissions, and $\mu_{t}$ is the fraction of emissions that are abated. Abating the fraction $\mu_{t}$ costs $z_{t}$ units of output:

$$
z_{t}=g\left(\mu_{t}\right) \cdot Y_{t}
$$

where $g(\cdot)$ relates $\mu_{t}$ to the fraction of output spent on abatement. Unabated emissions feeds back on output through its effect on the stock of pollution $x_{t}$, which evolves according to

$$
x_{t+1}=\lambda x_{t}+e_{t}+e_{t}^{\text {row }}
$$

where $\lambda$ is pollution's decay rate and $e_{t}^{\text {row }}$ represents emissions from the rest of the world.

\subsection{Decentralized Problem}

In this subsection, we specify the problems faced by the representative household and firm and characterize the decentralized competitive equilibrium. We allow for two policy variables: (i) an emissions tax, $\tau_{e t}$, paid by the firm on each unit of current emissions and (ii) a tax on vacancy creation, $\tau_{v t}$, paid by the firm as a fraction of their total vacancy positing costs $v_{t} G$. Either of these taxes could be negative, in which case they would be a subsidy. These two policies are analogous to the two policies introduced in the analytical model and they are intended to address the pollution and congestion externalities, respectively ${ }^{13}$ We refer to the case with $\tau_{e t}=\tau_{v t}=0 \forall t$ as the unregulated equilibrium.

\subsubsection{Household}

The representative household chooses current consumption and next period's capital in order to maximize its present discounted value of expected lifetime utility, treating the wage, $w_{t}$,

\footnotetext{
${ }^{13}$ The tax on vacancy creation is analogous to the hiring tax $H$, while the emissions tax is analogous to the employment tax $a$.
} 
rental rate on capital, $r_{t}$, and the job-finding rate, $f_{t}$ as exogenous.

$$
\begin{aligned}
& V\left(k_{t}, n_{t}\right)=\max _{c_{t}, k_{t+1}}\left[\ln c_{t}-\xi n_{t}+\beta E\left\{V\left(k_{t+1}, n_{t+1}\right)\right\}\right] \\
& \text { s.t. } \\
& \qquad c_{t}+k_{t+1}-(1-\delta) k_{t} \leq r_{t} k_{t}+w_{t} n_{t}+\tau_{e t} e_{t}+\tau_{v t} v_{t} G+\pi_{t} \\
& \qquad n_{t+1}=(1-s) n_{t}+f_{t}\left(1-n_{t}\right)
\end{aligned}
$$

$\beta$ denotes the subjective discount factor and $\xi$ denotes disutility from work. Equation 14 is the household's budget constraint. The left-hand side denotes expenditures on consumption and capital investment, while the right-hand side denotes the sources of income. Equation 15 is the evolution of employment from the perspective of the household and it reflects the fact that the household does not internalize how their search activity impacts the job-finding rate, $f_{t}$. The first-order and envelop conditions can be manipulated to yield:

$$
\begin{aligned}
& \beta E_{t}\left\{\frac{1}{c_{t+1}}\left[r_{t+1}+1-\delta\right]\right\}=\frac{1}{c_{t}} \\
& V_{n_{t}}=\frac{w_{t}}{c_{t}}-\xi+\left(1-s-f_{t}\right) \beta E_{t}\left\{V_{n_{t+1}}\right\}
\end{aligned}
$$

\subsubsection{Firm}

The representative firm maximizes the present discount value of expected lifetime profits, treating factor and output prices and the TFP shock as exogenous. The firm also faces the exogenous policy variablies $\tau_{e t}$ and $\tau_{v t}$. The firm's profit function is

$$
\pi_{t}=\left(1-g\left(\mu_{t}\right)\right) Y_{t}-\tau_{e t}\left(1-\mu_{t}\right) h\left(Y_{t}\right)-r_{t} k_{t}-w_{t} n_{t}-\left(1+\tau_{v t}\right) v_{t} G
$$

The first term on the right-hand side of equation 18 is the firm's output net of abatement expenditure, and the second term is the firm's tax bill on unabated emissions. The re- 
maining three terms are the firm's capital rental bill, wage bill, and tax-inclusive vacancy expenditures.

The firm's problem can be written as the following dynamic program.

$$
J\left(n_{t}, \theta_{t}\right)=\max _{k_{t}, \mu_{t}, v_{t}}\left[\pi_{t}+\beta E\left\{\frac{c}{c^{\prime}} J\left(n_{t+1} ; \theta_{t+1}\right)\right\}\right]
$$

s.t.

$$
n_{t+1}=(1-s) n_{t}+q_{t} v_{t}
$$

and equations 8 through 12 and 18 from above

Though there is just one representative firm, we model pollution's effect on output as an externality by assuming that the firm treats $x_{t}$ as exogenous. The firm chooses how much capital to rent, what fraction of emissions to abate, and how many vacancies to post, taking the wage, $w_{t}$, rental rate, $r_{t}$, and vacancy-filling rate, $q_{t}$, as exogenous ${ }^{14}$ Equation 19 is the evolution of labor from the perspective of the firm, and shows that the firm does not internalize how their choices affect the vacancy-filling rate $q_{t}$.

The firm's problem yields the following important equations:

$$
\begin{aligned}
& r_{t}=\left[1-g\left(\mu_{t}\right)-\tau_{e t}\left(1-\mu_{t}\right) h^{\prime}\left(Y_{t}\right)\right]\left(1-d\left(x_{t+1}\right)\right) \alpha \theta_{t}\left(\frac{k_{t}}{n_{t}}\right)^{\alpha-1} \\
& \tau_{e t} h\left(Y_{t}\right)=g^{\prime}\left(\mu_{t}\right) Y_{t} \\
& q_{t} \beta E_{t}\left\{\frac{c_{t}}{c_{t+1}} J_{n_{t+1}}\right\}=\left(1+\tau_{v t}\right) G \\
& J_{n_{t}}=\left[1-g\left(\mu_{t}\right)-\tau_{e t}\left(1-\mu_{t}\right) h^{\prime}\left(Y_{t}\right)\right]\left(1-d\left(x_{t+1}\right)\right)(1-\alpha) \theta_{t}\left(\frac{k_{t}}{n_{t}}\right)^{\alpha}-w_{t}+(1-s) \beta E_{t}\left\{\frac{c_{t}}{c_{t+1}} J_{n_{t+1}}\right\}
\end{aligned}
$$

where equation 20 states that the rental rate on capital equals the marginal product of capital less the costs imposed by the need for additional abatement or through the tax on unabated emissions. Similarly, equations 21 and 22 are marginal conditions on abatement

\footnotetext{
${ }^{14}$ The firm discounts future periods using the stochastic discount factor, $\beta E\left\{\frac{c}{c^{\prime}}\right\}$. As such, the firm discounts future values in a way that is consistent with household preferences.
} 
expenditures and vacancy creation respectively, while equation 23 is the marginal value of an additional worker to the firm.

\subsubsection{Wage Bargaining}

Wages are set through repeated Nash bargaining over the marginal surplus generated by a match. The solution to this problem is the following surplus sharing rule:

$$
b \frac{1}{c_{t}} J_{n_{t}}=(1-b) V_{n_{t}}
$$

where $b$ is workers' bargaining power ${ }^{15}$ Combining equations 17 and 22,24 yields:

$$
w_{t}=b\left(\left[1-g\left(\mu_{t}\right)-\tau_{e t}\left(1-\mu_{t}\right) h^{\prime}\left(Y_{t}\right)\right]\left(1-d\left(x_{t+1}\right)\right)(1-\alpha) \theta_{t}\left(\frac{k_{t}}{n_{t}}\right)^{\alpha}+\Phi_{t}\left(1+\tau_{v t}\right) G\right)+(1-b) \xi c_{t}
$$

where the first term in parentheses is the marginal product of a new worker less the costs imposed by additional abatement or the emissions tax, and the second term is the asset value of an employment match reflecting the vacancy costs saved by having an additional employed worker. The last term reflects the worker's disutility from work express in goods.

The decentralized equilibrium is fully characterized by the following set of equations: 10 , 13, 16, 19, 22, 25, the definitions of $q_{t}$ and $\Phi_{t}$, and the goods market clearing condition:

$$
c_{t}+k_{t+1}-(1-\delta) k_{t}+v_{t} G=\left(1-g\left(\mu_{t}\right)\right) Y_{t}
$$

These equations determine the 11 core endogenous variables of our model: $c_{t}, k_{t}, n_{t}, Y_{t}, v_{t}$, $q_{t}, \Phi_{t}, r_{t}, w_{t}, x_{t}, \mu_{t}$

\footnotetext{
${ }^{15}$ To ensure that the terms from the household's and firm's problems are measured in consistent units (utils), we weight $J_{n}$ by the marginal utility of consumption, $\frac{1}{c}$.
} 


\subsection{Planner's Problem}

Due to the presence of the pollution and congestion externalities, the solution to the decentralized problem presented above will not in general coincide with the efficient solution of the planner's problem where all externalities have been internalized $\sqrt{16}$ Comparisons of the unregulated decentralized equilibrium and the planner's allocation highlight the inefficiencies arising from both externalities.

The social planner chooses consumption, abatement, employment, and vacancies to maximize the discounted present value of household utility, internalizing all externalities. For example, the planner's problem recognizes how emissions from production affects future output, and how vacancies affect the number of job matches. See appendix section $B$ for the equations describing the planner's problem.

\subsection{Ramsey Efficient Dynamic Tax Problem}

In section 3.3, we treat the emissions tax $\tau_{e t}$ and the vacancy creation tax $\tau_{v t}$ as exogenous. However, we are interested in how the government could use these taxes to correct the market failures and reach the efficient allocation. To this end, we specify the government's problem as the Ramsey efficient dynamic tax problem. This problem is identical to the decentralized equilibrium described in section 3.3 , but with the additional choice over $\tau_{e t}$ and $\tau_{v t}$, subject to all of the constraints from the firm's and the household's optimization problems. Details of this optimization problem are in appendix section C.

If the government can choose both taxes, then it can correct both market failures and reach the efficient allocation from the planner's problem (as we will show in the simulations below). By solving this problem, we see the level and dynamics of the emissions tax and the vacancy creation tax needed to internalize both externalities. We refer to the taxes

\footnotetext{
${ }^{16}$ In the main paper, we only consider efficiency as our optimization criteria. However, in the appendix we present results highlighting the equity implications across policies.
} 
recovered this way as the "first-best" taxes. However, we are also interested in cases where one tax is fixed, while the other tax is optimized. Taxes recovered this way are referred to as "second-best" taxes. That is, the second-best emissions tax is found when the government sets $\left\{\tau_{e t}\right\}_{t=0}^{\infty}$ to maximize welfare given that $\tau_{v t}$ is fixed at some value (perhaps 0 ), and vice-versa for the second-best vacancy creation tax.

\section{Calibration}

We calibrate our decentralized model to replicate key features of the U.S. economy using both data and values reported in the existing literature. Each specification of our model is solved using standard linearization techniques $\$ 17$ and as we move across model specifications, say from the decentralized problem to the planner's problem, we keep all parameter values fixed at their calibrated levels. The next several subsections describe our calibration strategy; more details are in appendix section $\mathrm{D}$. The calibrated parameter values and their sources are summarized in Table 1 .

\subsection{RBC Parameters}

We set our model's period length to one quarter, and we follow the RBC literature and set the agent's subjective quarterly discount factor, $\beta$, equal to 0.983 , matching the real interest rate from U.S. data. Also following convention, we set the quarterly depreciation rate of private capital, $\delta$, to 0.025 , thereby targeting an annual depreciation rate of approximately 10 percent. We set capital's share of income, $\alpha$, equal to 0.36 , following the RBC literature. The persistence in the productivity shock process, $\rho_{\theta}$, and the standard deviation of the innovation in the shock process, $\sigma_{\theta}$ are set to 0.933 and 0.015 , respectively. These values were set so that our model generates a series for average labor productivity (output per

\footnotetext{
${ }^{17}$ Christiano (2002) discusses the linear methods used to approximate our model.
} 
worker) that matches the first-order autocorrelation and volatility of the series observed in the quarterly data (0.70 and 2.00 respectively). Lastly, the policy variables, $\tau_{e}$ and $\tau_{v}$ are both set to 0 in the baseline decentralized economy.

\subsection{Environmental Parameters}

The pollution stock decay rate $\lambda$ is calibrated based on the estimated half-life of atmospheric carbon dioxide. The Fifth Assessment Report of the IPCC, Working Group 1, provides a calculation that about $50 \%$ of a pulse of anthropogenic $\mathrm{CO}_{2}$ leaves the atmosphere after 50 years 18 Given our quarterly time scale, this implies a decay rate $\lambda=0.9965 .19$ Carbon emissions from the rest of the world $\left(e_{t}^{\text {row }}\right)$ are assumed to be exogenous and constant. Since the United States emits about one-sixth of global carbon dioxide, 20 we set $e_{t}^{\text {row }}=e^{\text {row }}$ to equal five times the steady-state value of domestic emissions $e_{t}$.

The relationship between baseline pollution and output is given by $h\left(y_{t}\right)=y_{t}^{1-\gamma}$, where $1-\gamma$ is the short-run elasticity of emissions with respect to output. In appendix section D.1, we describe a calibration strategy for this elasticity. We collect monthly data and run a simple set of regressions of the log of emissions on the log of output. We find a range of point estimates from about 0.4 to 0.9 (see Table D.1), and we use a value of 0.6 in the simulations. This is the value reported for the short-run (cyclical) greenhouse gas emissions elasticity with respect to output in the United States, from Cohen et al. (2018) ${ }^{21}$

\footnotetext{
${ }^{18}$ See Box 6.1 in Ciais et al. (2014).

${ }^{19}$ This exponential decay rate specification simplifies a much more complicated set of processes that govern the movement of $\mathrm{CO}_{2}$ in the atmosphere, including its interaction with the land and the ocean. Though about $50 \%$ leaves the atmosphere within 50 years, up to 15 to $40 \%$ can remain after 1,000 years. "This is why the concept of a single, characteristic atmospheric lifetime is not applicable to $\mathrm{CO}_{2}$." (Ciais et al. (2014), p. 473)

${ }^{20}$ https://www.epa.gov/ghgemissions/global-greenhouse-gas-emissions-dataCountry

${ }^{21}$ This is comparable to the value of 0.696 used in Heutel (2012), which was based on regressions using older data. The Heutel (2012) value was based on data on just $\mathrm{CO}_{2}$ emissions, rather than all greenhouse gases, and it used data from 1981 to 2003, rather than 1990 through 2014 as in Cohen et al. (2018). The data used in Heutel (2012) are monthly, while the data in Cohen et al. (2018) are annual. Doda (2014) finds a higher elasticity, 1.01, using annual data on $\mathrm{CO}_{2}$ emissions from $1950-2011$.
} 
The emissions abatement cost and pollution damage functions are calibrated from the DICE model (Nordhaus, 2018). The most recent version of DICE available on William Nordhaus's website is the DICE 2016R2 version.22 The emissions abatement cost function $g$ is taken directly from DICE. The functional form is: $g\left(\mu_{t}\right)=\theta_{1} \mu_{t}^{\theta_{2}}$. The exponent $\theta_{2}$ is 2.6 , and the coefficient $\theta_{1}$ is $0.074{ }^{23}$ These values imply that the cost to abate $50 \%$ of gross emissions equals $1.22 \%$ of gross output, while the cost to abate $100 \%$ of gross emissions equals $7.4 \%$ of gross output.

In DICE, damages are a function of temperature rather than of atmospheric carbon concentrations. A dynamic climate model describes how carbon concentrations affect temperature over time. Our model does not include temperature or a carbon cycle model, so we approximate DICE's damage function by setting damages to be a function of the pollution stock $x$. Details of the calibration strategy are in appendix section D.2. We use the same functional form and calibration strategy as in Heutel (2012), though based now on the most recent version of DICE (2016R2). The damage function $d(x)$ is quadratic: $d(x)=d_{2} x^{2}+d_{1} x+d_{0}$, where $d_{2}=1.05 e-8, d_{1}=8.10 e-6$, and $d_{0}=-0.0076$, and the units of the pollution stock $x$ are gigatons of carbon (GtC). These parameters imply that at the current level of atmospheric carbon stock (851 GtC, from DICE 2016R2), the damages from climate change amount to $0.69 \%$ of gross output. A doubling of the current carbon stock (to $1702 \mathrm{GtC}$ ) would increase that to $3.66 \%$ of gross output.

\footnotetext{
${ }^{22}$ Details available at https://sites.google.com/site/williamdnordhaus/dice-rice

${ }^{23}$ The DICE model allows for the coefficient $\theta_{1}$ to decrease over time to capture growth in abatement technology. We abstract from growth and thus keep $\theta_{1}$ constant at its initial value.
} 


\subsection{Labor Market Parameters}

We follow Shimer (2005) and set the exponent in the matching function, $\gamma_{2}$, to 0.72. ${ }^{24}$ We follow Christiano et al. (2016) and Atolia et al. (2019) and set vacancy posting costs, $G$, to a low value so that total spending on vacancy creation averages between 1 and 2 percent of total output. Next, we simultaneously set the coefficient in the matching function, $\gamma_{1}$, the agent's disutility of work, $\xi$, and the separation rate, $s$, to match the following targets from Atolia et al. (2019): a mean job-finding rate of 0.59, a mean labor market tightness of 0.72 , and a steady-state unemployment rate of 7.8 percent. This strategy yields the following parameter values: $\gamma_{1}=0.6425 ; \xi=0.8565 ; x=0.05$. Finally, in the spirit of Hagedorn and Manovskii (2008), we set workers' bargaining power, $b$, to a low value to target the elasticity of wages with respect to average labor productivity, yielding $b=0.05$.

Because our calibrated workers' bargaining power $(b=0.05)$ is significantly lower than the coefficient on unemployment in the matching function $\left(\gamma_{2}=0.72\right)$, the analytical model tells us that the Hosios condition is not satisfied and that the equilibrium number of job vacancies will be higher than the efficient level. We explore the policy implications of this in the simulations below, and we also conduct sensitivity analysis over bargaining power.

\section{Results}

First, we compare the unregulated decentralized equilibrium to the planner's solution to show how the pollution and congestion externalities distort the equilibrium allocation. Next, we consider the first-best policy response of the government, using both the emissions tax and the vacancy creation tax to internalize all externalities and bring the decentralized economy

\footnotetext{
${ }^{24}$ This value was originally derived by estimating the matching function (equation 6) using data on the number of unemployed individuals reported by the Bureau of Labor Statistics, the number of active vacancies reported in the Conference Board Help Wanted Index, and estimates of the job-finding rate from the sample period 1951-2003.
} 
in-line with the planner's solution. Lastly, we model the second-best tax problem, where the government is allowed to optimize one tax instrument while the other is fixed at zero.

\subsection{Decentralized Versus Planner's Problem}

Before we compare the unregulated decentralized equilibrium and the planner's solution, we verify that our decentralized model generates moments consistent with those from the existing literature. The first panel of Table 2 shows that the mean and volatility of output are 3.04 and 2.25 under the unregulated decentralized equilibrium. The mean and volatility of consumption are 2.36 and 0.88 , and the mean and volatility of investment are 0.64 and 6.99. These moments reflect realistic shares of consumption and investment in output and are consistent with consumption smoothing and investment that is significantly more volatile than output. The second panel of Table 2 provides the means of unemployment, vacancies, and labor market tightness, which are targets in our calibration strategy, and shows that each of these labor market variables are more volatile than output is in the decentralized economy. High labor market volatility is consistent with U.S. data, though we are unable to match the exact level of volatility with our baseline model 25 The third panel of Table 2 shows that the volatility of emissions is 1.35 , while the fraction of emissions abated and abatement spending are both equal to 0 in the unregulated decentralized economy.

Figure 1 presents time paths for key model variables recovered from both the decentralized and planner's problems. The simulations are for 100 periods under a random draw of innovations (an identical draw for both the planner's and the decentralized model). The first four panels of Figure 1 show how the time paths of output, consumption, vacancies, and unemployment deviate between the decentralized and planner's problems. The congestion externality results in an oversupply of vacancies, which in turn results in additional output.

\footnotetext{
${ }^{25}$ See Atolia et al. (2018) and Atolia et al. $(2019)$ for more details on the difficulties matching labor market volatility using RBC search models.
} 
The pollution externality also results in a higher level of output than is efficient. Thus, the two market failures reinforce each other. This point will be revisited when we consider the government's first- and second-best policy options in the next few subsections. The bottom two panels of Figure 1 demonstrate the gaps that exist in emissions and abatement across the two model environments. In the unregulated decentralized model, firms have no incentive to abate, so abatement is constant at zero.

We compare the first and second moments of key outcome variables in Table 2. Inspection of this table reveals the differences in the mean and volatility of our key variables across the decentralized and planner's problems. While the traditional RBC variables are only moderately impacted by the change in model specification, we find significant differences in labor market variables. These large differences in means come from the congestion externality, which causes firms to create more vacancies than is efficient. Because the Hosios condition is not met, and in fact the bargaining parameter $b$ is so much lower than the match function elasticity $\gamma_{2}$, the net congestion externality results in a vast oversupply of employment; the efficient unemployment rate $(13.73 \%)$ is nearly double the unregulated decentralized unemployment rate $(7.87 \%)$.

As for environmental variables, the third panel of Table 2 shows that mean emissions falls from 1.9470 to 1.8266 as we move from the decentralized problem to the planner's problem. This follows from the negative externality of pollution. While the volatility of emissions and pollution is similar across specifications, the fraction of emissions abated and total spending are volatile under the planner's problem. More simulation results under both the decentralized and planner's models are provided in appendix section E.

We measure the welfare effect of the market failures by calculating the compensating variation for the unregulated decentralized economy, that is, the amount of additional consumption the representative household must be given in the unregulated decentralized equilibrium to make her as well off (equal lifetime utility) as the representative household under 
the planner's allocation. In doing this calculation, we initialize all state variables to their unregulated decentralized steady-state values and subject both systems to the same sequence of productivity shocks. As such, this welfare measure accounts for both business cycle fluctuations and the transition from the unregulated decentralized equilibrium to the equilibrium of the planner's problem ${ }^{26}$ The compensating variation of the decentralized equilibrium is $1.177 \%$; that is, agents in the decentralized economy would have to be given $1.177 \%$ more consumption each period in order to be made indifferent between the decentralized economy and the planner's economy that corrects the externalities.

\subsection{First-Best Tax Problem}

We now consider the solution under the efficient Ramsey tax, where the government sets an emissions tax and a vacancy tax or subsidy to internalize both externalities. Under the first-best taxes, the equilibrium coincides with that of the planner (and thus all outcomes under the first-best taxes are identical to those under the planner's problem reported in Table 2). Because vacancies in the unregulated equilibrium are higher than in the efficient planner's problem, a tax (not a subsidy) on vacancies is efficient. The steady-state value of the efficient vacancy creation tax is $\tau_{v}=10.96$. This corresponds to about a $1,100 \%$ ad valorem tax rate on vacancies; for every dollar that the firm spends on vacancy posting costs, it pays 11 dollars in the tax. This enormous tax rate reflects the large difference between the efficient and the decentralized unemployment rates ${ }^{27}$ The steady-state value of the efficient emissions tax is $\tau_{e}=8.6136 e^{-4}$, which is in arbitrary units of the DSGE model. When we

\footnotetext{
${ }^{26}$ Initializing all state variables to the same level when computing welfare effects is necessary in our model since the change in specifications has a dramatic effect on the steady-state level of some variables (namely pollution and unemployment). Steady-state utility under the second-best emissions tax is actually higher than the steady-state utility under the first-best taxes. This surprising result is explored in appendix section F where we present transition dynamics across policies.

${ }^{27}$ The impact of the vacancy creation tax on the share of output directed to vacancy creation is not as extreme. Specifically, after-tax spending on vacancy creation rises from approximately $1.4 \%$ of GDP in the baseline decentralized equilibrium to approximately $3.6 \%$ in the efficient tax equilibrium.
} 
convert this to dollars per metric ton of carbon dioxide via a back-of-the-envelope technique, it is equal to 2.21 dollars per ton of $\mathrm{CO}_{2}{ }^{28}$ This is more than an order of magnitude lower than most estimates of the efficient carbon tax (the social cost of carbon) that come from models like DICE. This is because of the large congestion externalities from the labor market exacerbating the pollution externality; the resulting first-best vacancy tax also substantially reduces emissions, leaving less lifting needed to be done by the emissions tax.

Figure 2 presents impulse response functions (IRFs) for each of the two first-best taxes in response to a one-standard-deviation productivity shock. The emissions tax increases by nearly $1.5 \%$ at maximum, but this effect is delayed over a period of about 10 quarters. The unregulated contemporaneous increase in emissions from a positive productivity shock is muted under efficient dynamic taxes, a result that is also found in Heutel (2012). The vacancy tax rate decreases by about $2 \%$, indicating that the increase in vacancies posted after the productivity shock is muted. These properties of the two taxes are also demonstrated in the appendix in Figure E.5, which simulates them under a business cycle. The emissions tax is procyclical, and the vacancy creation tax is countercyclical.

When productivity increases, the negative pollution externality is exacerbated, so the efficient emissions tax rises to overcome this. However, when productivity increases, the labor search congestion externality is lessened; the efficient vacancy tax is reduced to accommodate this. It is not obvious ex ante that the congestion externality decreases after a positive productivity shock. The congestion externality is actually the net externality of the pair of congestion externalities - one caused by the firm and one by the workers. Both of these congestion externalities increase following a positive productivity shock, but the one that leads to too little employment increases by more than the one that leads to too much employment. That scenario yields the observed countercyclical behavior of the efficient vacancy tax.

\footnotetext{
${ }^{28}$ To convert, we equilibrate the steady-state level of output in our model to U.S. GDP (\$20 trillion) and we equilibrate steady-state (unregulated) emissions to total U.S. emissions (5 million tons $\mathrm{CO}_{2}$ ).
} 


\subsection{Second-Best Tax Problem}

Table 3 presents the mean and volatility of several variables under the solutions with the second-best emissions tax and the second-best vacancy tax. Focusing on the RBC variables, the second-best emissions tax results in mean values that are very close to that found in the unregulated decentralized economy, while the second-best vacancy tax results in mean values that are almost identical to the mean values recovered from the planner's problem. From looking at the RBC variables alone, it appears that the second-best vacancy tax is more efficient than the second-best emissions tax.

The next two panels of Table 3 show that the two second-best taxes have different effects on different parts of the economy. The second-best vacancy tax, which targets the labor market, results in mean labor market variables that are almost identical to the planner's problem values. The second-best emissions tax brings the unemployment and vacancy rates somewhat closer to their efficient values, but not all the way there. For the environmental variables, the second-best emissions tax actually results in an overshoot - lower emissions and higher abatement than the efficient level. The fraction of emissions abated under the second-best emissions tax is an order of magnitude higher than the efficient fraction abated (23\% vs. 2.6\%). Because the second-best emissions tax is also being asked to address the large congestion externalities, it must overshoot in addressing the pollution externality. The second-best vacancy tax reduces emissions by only a very small amount because of the reduction in employment; there is still no abatement spending without an emissions tax.

In Figures 3 and 4 , we explore how the steady-state levels of the second-best taxes respond to the level of the constrained tax. While in Table 3, the constrained tax is constrained at zero, these figures consider other non-zero values of the constrained tax. Figure 3 presents the results when the vacancy creation tax is constrained, and the emissions tax responds optimally. The x-axis of Figure 3 is the constrained level of the vacancy creation tax. It is centered at about 10.96, which is its first-best steady-state level (a 1,096\% tax rate). At that 
level, the optimized emissions tax is about 2.21 dollars per ton, its first-best steady-state level. However, when the vacancy creation tax is constrained to be higher, the second-best emissions tax is somewhat lower. This reflects the fact that both taxes are addressing market failures that go in the same direction (too much production). When one tax is higher than first-best, the other tax is lower. When the vacancy tax approaches zero (i.e., when this policy is absent), the second-best emissions tax is much higher than its first-best level. In fact, it is about 33 times greater than its first-best level when the vacancy tax is zero, or about 73.41 dollars per ton.

Figure 4 repeats this exercise, but it considers the second-best vacancy creation tax in response to a constrained emissions tax. Again, when one tax is higher than its first-best level (here the emissions tax), the second-best level of the other tax (here the vacancy creation tax) is lower than its first-best level. In contrast to the results in Figure 3, the secondbest steady-state level of the vacancy creation tax does not vary by all that much as the constrained level of the emissions tax varies. Even with an emissions tax constrained at zero, the second-best vacancy creation tax is less than $1 \%$ greater than its first-best level. Thus, while second-best considerations affect the values of both taxes, the second-best adjustment to the emissions tax is much greater than the second-best adjustment to the vacancy tax.

Next, we consider the dynamic properties of the second-best taxes and how they compare to those of the first-best taxes. The right side of Table 3 shows the volatilities for various variables under the second-best taxes. There is not much difference in the RBC variables' volatilities. The vacancy tax yields much lower volatility for the labor market variables than does the emissions tax, and the volatilities match those of the planner's problem. There is not much difference in volatilities across the taxes for the environmental variables, except that there is no abatement without an emissions tax and thus no volatility in abatement.

Figure 5 presents IRFs for both taxes' first-best values and second-best values when the other tax is constrained to zero. The top panel shows that both the first-best and the 
second-best emissions taxes are procyclical, but the second-best emissions tax is less so. This reflects the fact that the second-best emissions tax must account for both the pollution externality and the labor search congestion externalities. Because the first-best vacancy tax is countercyclical (from Figure 2), when the emissions tax is second-best and has to "pick up the slack" for the missing vacancy tax, it trades off between the procyclicality desired from the emissions tax and the countercyclicality desired from the vacancy tax.

The bottom panel shows that the second-best vacancy creation tax (when the emissions tax is zero) is almost exactly as countercyclical as the first-best vacancy creation tax. This again reflects the fact that the second-best vacancy tax brings the equilibrium closer to the planner's problem solution than does the second-best emissions tax. The large difference in the dynamic properties of the first-best and second-best emissions taxes can also be seen in Figure E.6 in the appendix, which simulates business cycle properties of the taxes.

The welfare implications of the second-best taxes are calculated using the same methodology as we used for welfare implications of the decentralized economy: we calculate the compensating variation for each policy relative to the planner's problem. For the secondbest emissions tax, this compensating variation is $0.945 \%$, and for the second-best vacancy tax, it is $0.010 \%$. While implementing either of the second-best taxes improves welfare relative to the unregulated decentralized equilibrium, the second-best vacancy tax is much more efficient than the second-best emissions tax. This reinforces our findings that the secondbest vacancy tax comes closer to matching the planner's solution than does the second-best emissions tax.

\subsection{Additional Analyses}

In the appendix, we present results from additional analyses. First, appendix section $\mathrm{G}$ presents results from sensitivity analyses. We vary the values of two parameters that determine the magnitude of the externalities: the worker's bargaining power $b$ and the damage 
from pollution $d(x)$. With a higher value of worker bargaining power $b$, the labor search congestion externalities created by the worker become larger while the externalities created by the firm become smaller. As a result, the magnitude of the efficient vacancy tax becomes smaller. When the worker bargaining power $b$ exceeds the match function elasticity $\gamma_{2}$, the analytical model tells us that the efficient vacancy tax becomes a vacancy subsidy; we demonstrate this in appendix section G. Finally, appendix section G also explores how the magnitude of the pollution externality affects both tax rates. A higher magnitude of the pollution externality of course implies a higher efficient emissions tax, but it can also affect the vacancy tax.

Second, appendix section $\mathrm{H}$ presents results from simulations that explore the equity implications of our model. Up to this point, the only social optimization criterion considered is efficiency, and the calibrated parameters imply that the efficient allocation involves a

much higher unemployment rate than the unregulated equilibrium. Appendix section $\mathrm{H}$ shows that the efficient allocation disproportionately benefits firms relative to workers. In that section we also perform an analysis where we add a parameter representing disutility from unemployment, which creates a social cost to unemployment beyond merely foregone production. With that disutility, the efficient level of unemployment is much lower.

\section{Conclusion}

We develop a dynamic stochastic general equilibrium model that includes autocorrelated productivity shocks, congestion externalities arising from labor market search frictions, and a pollution externality to examine the relationship between environmental policy and unemployment over the business cycle. In our benchmark calibrated model, the level of employment is inefficiently high both because of labor search congestion externalities and the pollution externality. When the government sets both an emissions tax and a vacancy cre- 
ation tax, the efficient allocation is achieved. We also consider second-best taxes, where only one of those two policies is available. This second-best emissions tax is 33 times larger than the first-best emissions tax and responds to productivity shocks in a different way.

Like other DSGE models, ours uses many simplifying assumptions to yield our main results. The model could be extended in many ways by exploring the importance of these assumptions. For example, one extension to this paper would be to incorporate multiple sectors rather than just a representative firm, as in Dissou and Karnizova 2016). Specifically, understanding the connection between environmental policies, the development of abatement technology, and the allocation of labor across output and "green technology" sectors is of interest. This concept of multiple productive sectors could also be extended to allow for a segmented labor market, at which point the model would be capable of addressing the reallocation of workers following a large policy shock. The optimal policies that we model only address total social efficiency and ignore distributional or equity issues. We find that the efficient equilibrium features a higher level of unemployment than the unregulated equilibrium; thus increasing efficiency likely comes at the cost of reducing equity. A social welfare function that includes equity objectives would likely yield a different set of first-best policies.

Our research has important policy implications. Policy makers are concerned over both efficiency and equity, and many models of optimal environmental policy ignore distributional concerns like the effects of policies on unemployment. Furthermore, even absent any concerns about equity and distributional outcomes, we show how the incorporation of labor frictions and unemployment into a model of optimal environmental policy can affect efficiency, given that the labor frictions create distortions. The Great Recession has made clear the fact that policy makers care about the cyclical effects of policies, and it is important to consider how various policies, like environmental and labor policies, interact over the business cycle. 


\section{References}

Andolfatto, D. (1996). Business cycles and labor-market search. The american economic review, pages $112-132$.

Annicchiarico, B. and Di Dio, F. (2015). Environmental policy and macroeconomic dynamics in a new keynesian model. Journal of Environmental Economics and Management, 69:121.

Atolia, M., Gibson, J., and Marquis, M. (2018). Labor market volatility in the rbc search model: A look at hagedorn and manovskiis calibration. Computational Economics, pages $1-20$.

Atolia, M., Gibson, J., and Marquis, M. (2019). Moral hazard in lending and labor market volatility. Journal of Money, Credit and Banking, 51(1):79-109.

Aubert, D. and Chiroleu-Assouline, M. (2019). Environmental tax reform and income distribution with imperfect heterogeneous labour markets. European Economic Review.

Barrage, L. (2020). Optimal dynamic carbon taxes in a climate-economy model with distortionary fiscal policy. The Review of Economic Studies, 87(1):1-39.

Blanchard, O. and Galí, J. (2010). Labor markets and monetary policy: A new keynesian model with unemployment. American economic journal: macroeconomics, 2(2):1-30.

Christiano, L., Eichenbaum, M., and Trabandt, M. (2016). Unemployment and business cycles. Econometrica, 84(4):1523-1569.

Christiano, L. J. (2002). Solving dynamic equilibrium models by a method of undetermined coefficients. Computationa Economics, 20(1):21-55.

Ciais, P., Sabine, C., Bala, G., Bopp, L., Brovkin, V., Canadell, J., Chhabra, A., DeFries, R., Galloway, J., Heimann, M., et al. (2014). Carbon and other biogeochemical cycles. In Climate change 2013: the physical science basis. Contribution of Working Group I to the Fifth Assessment Report of the Intergovernmental Panel on Climate Change, pages 465-570. Cambridge University Press.

Classen, T. J. and Dunn, R. A. (2012). The effect of job loss and unemployment duration on suicide risk in the united states: A new look using mass-layoffs and unemployment duration. Health economics, 21(3):338-350.

Cohen, G., Jalles, J. T., Loungani, P., and Marto, R. (2018). The long-run decoupling of emissions and output: Evidence from the largest emitters. Energy Policy, 118:58-68.

Diamond, P. A. (1982). Aggregate demand management in search equilibrium. Journal of political Economy, 90(5):881-894. 
Dissou, Y. and Karnizova, L. (2016). Emissions cap or emissions tax? a multi-sector business cycle analysis. Journal of Environmental Economics and Management, 79:169-188.

Doda, B. (2014). Evidence on business cycles and co2 emissions. Journal of Macroeconomics, 40:214-227.

Fischer, C. and Heutel, G. (2013). Environmental macroeconomics: Environmental policy, business cycles, and directed technical change. Annu. Rev. Resour. Econ., 5(1):197-210.

Fischer, C. and Springborn, M. (2011). Emissions targets and the real business cycle: Intensity targets versus caps or taxes. Journal of Environmental Economics and Management, $62(3): 352-366$.

Hafstead, M. A. and Williams, R. C. (2018). Unemployment and environmental regulation in general equilibrium. Journal of Public Economics, 160:50-65.

Hafstead, M. A., Williams, R. C., and Chen, Y. (2018). Environmental policy, fullemployment models, and employment: A critical analysis. Technical report, National Bureau of Economic Research.

Hagedorn, M. and Manovskii, I. (2008). The cyclical behavior of equilibrium unemployment and vacancies revisited. American Economic Review, 98(4):1692-1706.

Heutel, G. (2012). How should environmental policy respond to business cycles? optimal policy under persistent productivity shocks. Review of Economic Dynamics, 15(2):244264.

Hohberger, S., Priftis, R., and Vogel, L. (2020). The distributional effects of conventional monetary policy and quantitative easing: Evidence from an estimated dsge model. Journal of Banking \& Finance, 113:105483.

Hosios, A. J. (1990). On the efficiency of matching and related models of search and unemployment. The Review of Economic Studies, 57(2):279-298.

Iacoviello, M. (2005). House prices, borrowing constraints, and monetary policy in the business cycle. American economic review, 95(3):739-764.

Jaffe, A. B., Newell, R. G., and Stavins, R. N. (2005). A tale of two market failures: Technology and environmental policy. Ecological economics, 54(2-3):164-174.

Jarociński, M. and Karadi, P. (2020). Deconstructing monetary policy surprisesthe role of information shocks. American Economic Journal: Macroeconomics, 12(2):1-43.

Kahneman, D. and Sugden, R. (2005). Experienced utility as a standard of policy evaluation. Environmental and resource economics, 32(1):161-181.

Kaplan, G., Moll, B., and Violante, G. L. (2018). Monetary policy according to hank. American Economic Review, 108(3):697-743. 
Kassenboehmer, S. C. and Haisken-DeNew, J. P. (2009). Youre fired! the causal negative effect of entry unemployment on life satisfaction. The Economic Journal, 119(536):448462.

Kennedy, P. W. (1994). Equilibrium pollution taxes in open economies with imperfect competition. Journal of environmental economics and management, 27(1):49-63.

Kunze, L. and Suppa, N. (2017). Bowling alone or bowling at all? the effect of unemployment on social participation. Journal of Economic Behavior \& Organization, 133:213-235.

Lu, C.-H. (2019). Optimal government policies related to unemployment. Public Finance Review, 47(1):87-111.

Marcus, J. (2013). The effect of unemployment on the mental health of spouses-evidence from plant closures in germany. Journal of health economics, 32(3):546-558.

Merz, M. (1995). Search in the labor market and the real business cycle. Journal of monetary Economics, 36(2):269-300.

Milner, A., Page, A., and LaMontagne, A. D. (2013). Long-term unemployment and suicide: a systematic review and meta-analysis. PloS one, 8(1).

Mortensen, D. T. and Pissarides, C. A. (1994). Job creation and job destruction in the theory of unemployment. The review of economic studies, 61(3):397-415.

Mortensen, D. T. and Pissarides, C. A. (2001). Taxes, subsidies and equilibrium labour market outcomes.

Nordhaus, W. (2018). Evolution of modeling of the economics of global warming: Changes in the dice model, 1992-2017. Climatic change, 148(4):623-640.

Pissarides, C. A. (2000). Equilibrium unemployment theory. MIT press.

Pissarides, C. A. et al. (1985). Short-run equilibrium dynamics of unemployment vacancies, and real wages. American Economic Review, 75(4):676-690.

Rogerson, R., Shimer, R., and Wright, R. (2005). Search-theoretic models of the labor market: A survey. Journal of economic literature, 43(4):959-988.

Shi, S. and Wen, Q. (1999). Labor market search and the dynamic effects of taxes and subsidies. Journal of Monetary Economics, 43(2):457-495.

Shimer, R. (2005). The cyclical behavior of equilibrium unemployment and vacancies. American economic review, 95(1):25-49.

Stock, J. and Watson, M. (2000). Distribution of quarterly values of gdp/gdi across months within the quarter. Accessed: 7 April 2020. 


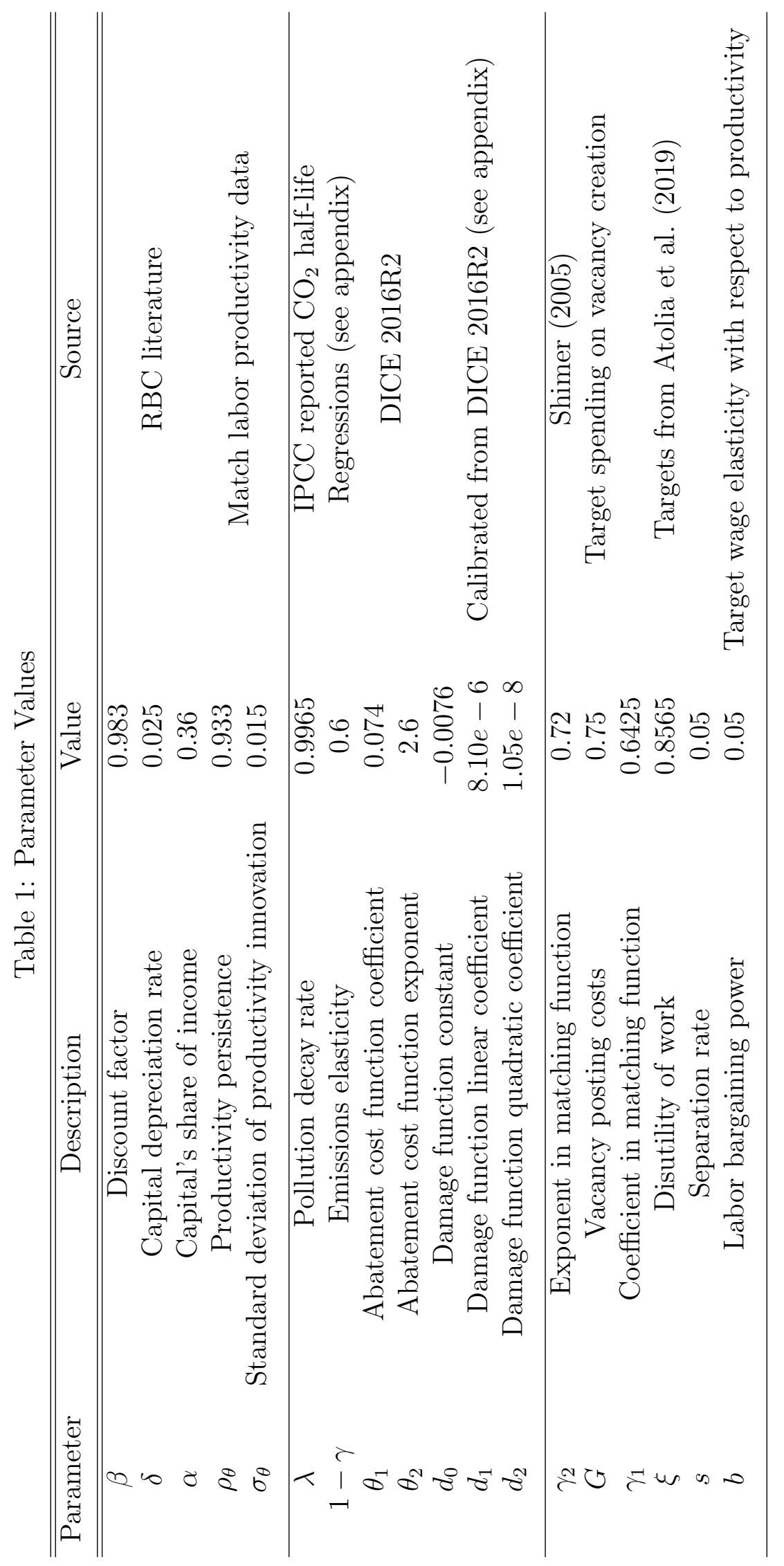


Figure 1: Business Cycle Simulations - Decentralized Vs. Planner
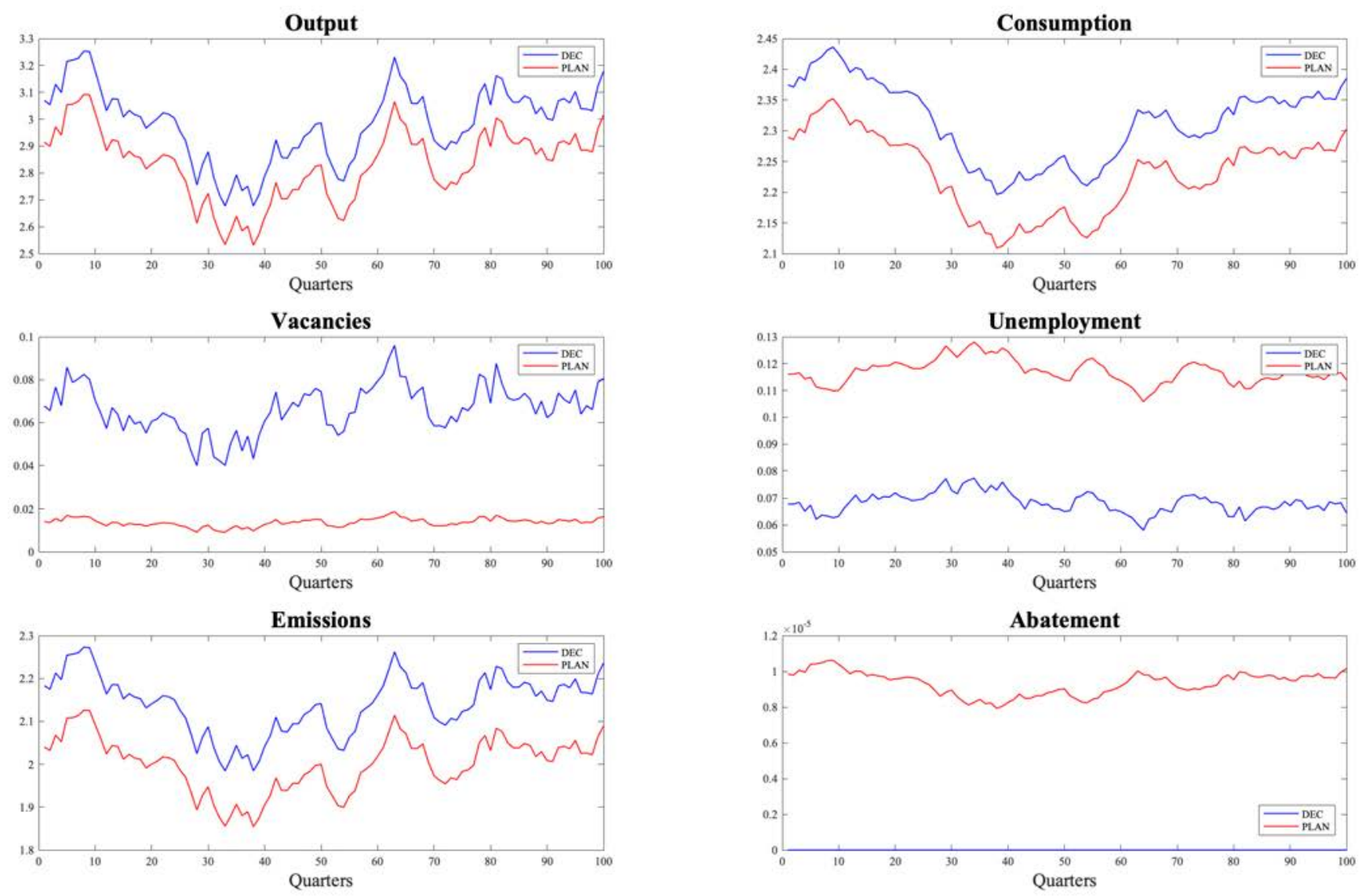

Notes: All simulations are from randomly generated draws of productivity innovations for 100 periods. 
Table 2: Decentralized vs Planner Outcomes

\begin{tabular}{|c|c|c|c|c|}
\hline & \multicolumn{2}{|c|}{ Mean } & \multicolumn{2}{|c|}{ \%-Volatility } \\
\hline & Decentralized & Planner & Decentralized & Planner \\
\hline \multicolumn{5}{|c|}{ RBC Variables } \\
\hline Output & 3.04 & 2.85 & 2.25 & 2.22 \\
\hline Consumption & 2.36 & 2.24 & 0.88 & 0.94 \\
\hline Investment & 0.64 & 0.60 & 6.99 & 7.41 \\
\hline \multicolumn{5}{|c|}{ Labor Market Variables } \\
\hline Unemployment & 0.0787 & 0.1373 & 4.07 & 1.95 \\
\hline Vacancies & 0.0565 & 0.0107 & 18.65 & 10.76 \\
\hline Labor Market Tightness & 0.7385 & 0.0786 & 20.82 & 11.65 \\
\hline \multicolumn{5}{|c|}{ Environmental Variables } \\
\hline Emissions & 1.9470 & 1.8266 & 1.35 & 1.32 \\
\hline Pollution & 3333.23 & 3123.78 & $2.98 e^{-003}$ & $2.97 e^{-003}$ \\
\hline Fraction Abated & 0 & 0.0263 & 0 & 0.19 \\
\hline Abatement Spending & 0 & $1.64 e^{-005}$ & 0 & 2.67 \\
\hline
\end{tabular}

Notes: This table presents the mean and volatility for the given variables under both the decentralized model with no policy variables and the planner's firstbest problem. Units of all variables are arbitrary, except unemployment is a rate and abatement is a fraction. Percent volatility is measured as the percent standard deviation of the cyclical component of the $\log$ of $x$, where the cyclical component is found by hp-filtering with a shading parameter of 1,600 . 
Table 3: Second-Best Outcomes

\begin{tabular}{|c|c|c|c|c|}
\hline & \multicolumn{2}{|c|}{ Mean } & \multicolumn{2}{|c|}{ \%-Volatility } \\
\hline & Emissions Tax & Vacancy Tax & Emissions Tax & Vacancy Tax \\
\hline \multicolumn{5}{|c|}{ RBC Variables } \\
\hline Output & 3.03 & 2.85 & 2.27 & 2.22 \\
\hline Consumption & 2.36 & 2.24 & 0.90 & 0.94 \\
\hline Investment & 0.63 & 0.60 & 7.14 & 7.41 \\
\hline \multicolumn{5}{|c|}{ Labor Market Variables } \\
\hline Unemployment & 0.0839 & 0.1373 & 4.33 & 1.95 \\
\hline Vacancies & 0.0469 & 0.0107 & 22.15 & 10.76 \\
\hline Labor Market Tightness & 0.5778 & 0.0785 & 24.29 & 11.65 \\
\hline \multicolumn{5}{|c|}{ Environmental Variables } \\
\hline Emissions & 1.4947 & 1.8731 & 1.34 & 1.33 \\
\hline Pollution & 2558.76 & 3206.62 & $3.02 e^{-003}$ & $2.98 e^{-003}$ \\
\hline Fraction Abated & 0.2305 & 0 & 0.18 & 0 \\
\hline Abatement Spending & 0.0049 & 0 & 2.51 & 0 \\
\hline
\end{tabular}

Notes: This table presents the mean and volatility for the given variables under the second-best emissions tax and the second-best vacancy tax. Units of all variables are arbitrary, except unemployment is a rate and abatement is a fraction. Percent volatility is measured as the percent standard deviation of the cyclical component of the log of $x$, where the cyclical component is found by hp-filtering with a shading parameter of 1,600 . 
Figure 2: Impulse Response Functions - First-Best Taxes

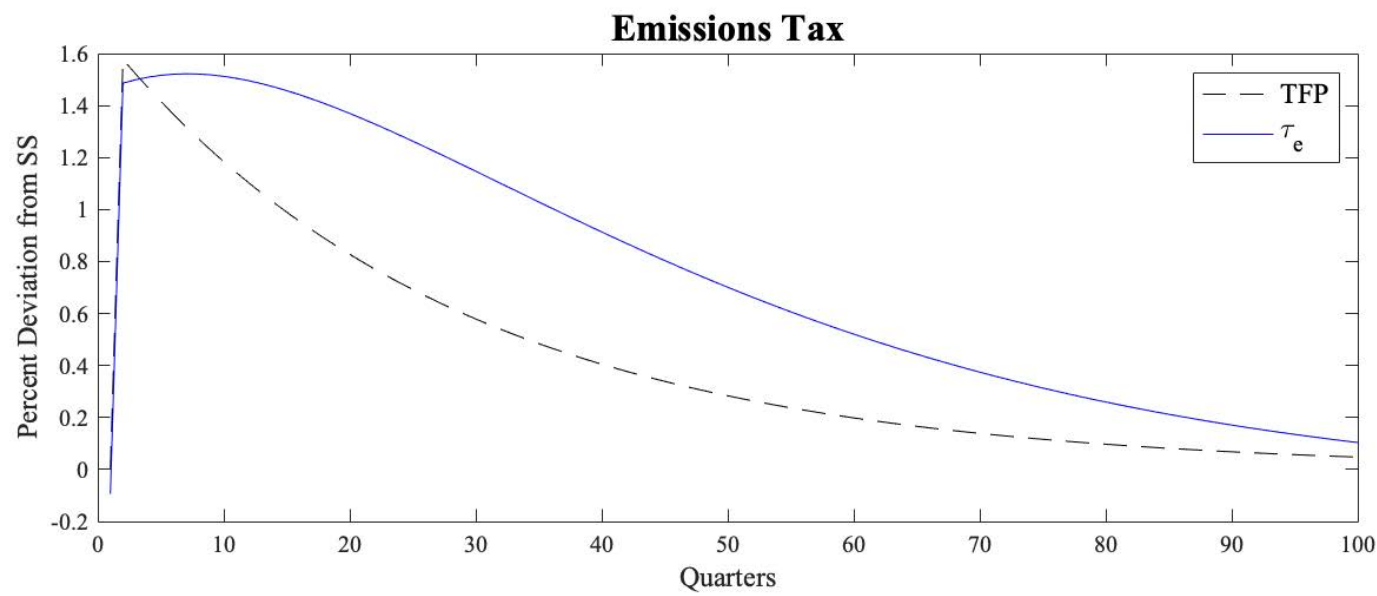

Vacancy Creation Tax

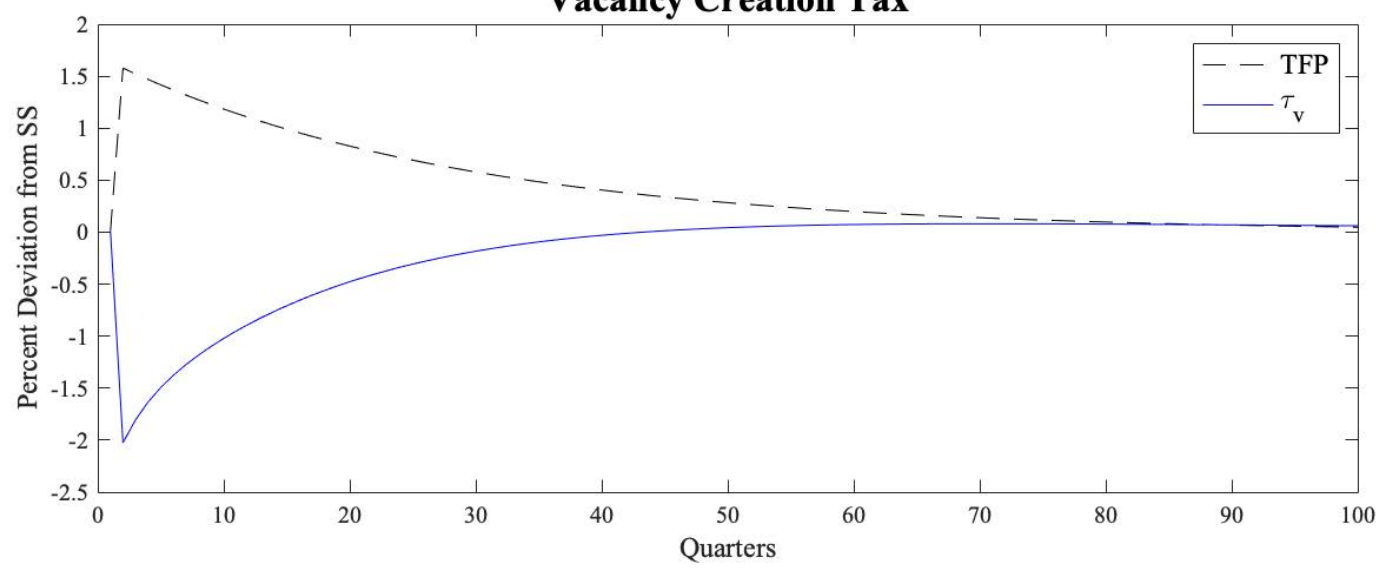

Notes: All simulations are from a one-unit one-time productivity innovation. 
Figure 3: Second-Best Emissions Tax

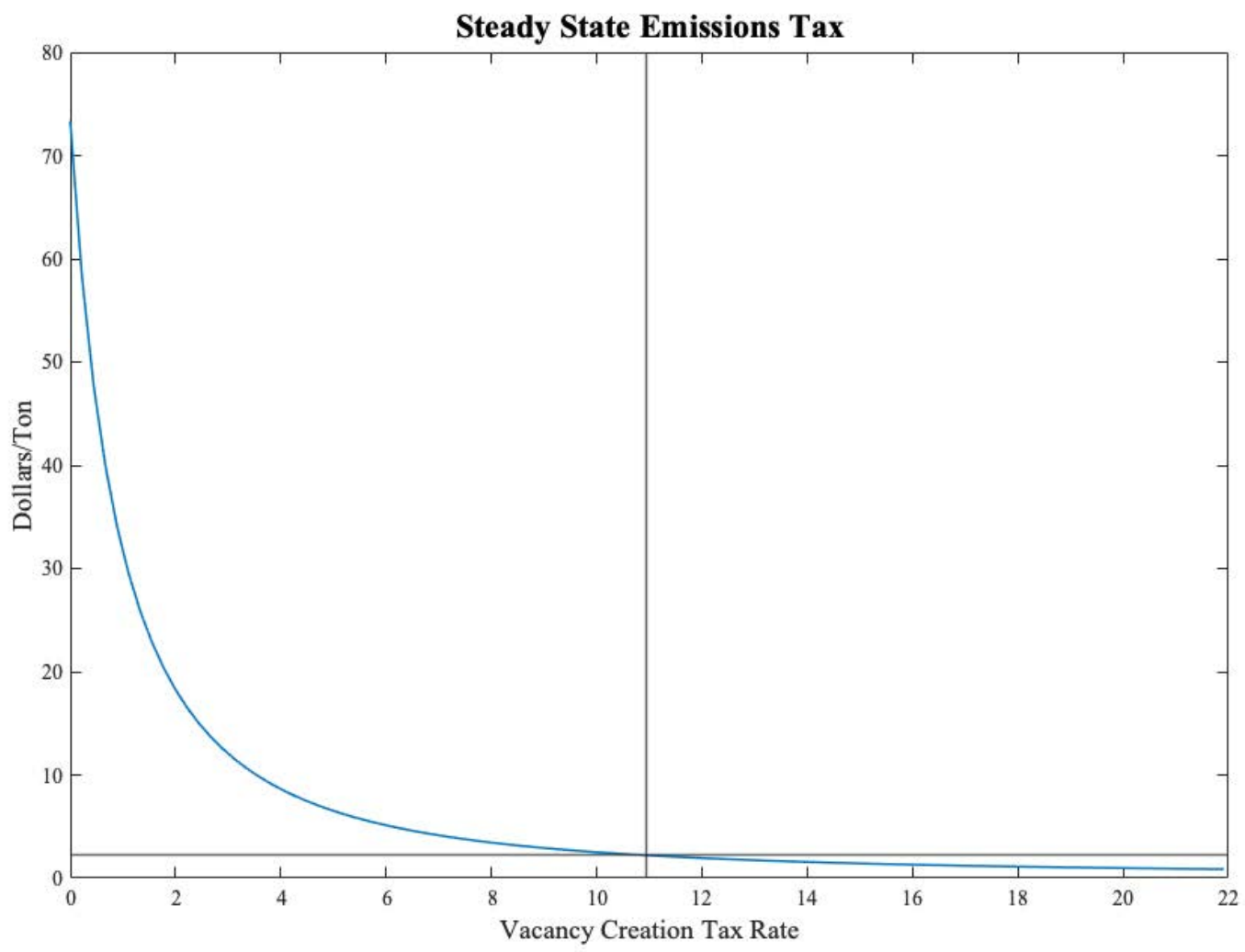

Notes: This figure is generated by solving for the (second-best) optimal emissions tax while varying the vacancy creation tax from 0 to twice its (first-best) optimal level. 
Figure 4: Second-Best Vacancy Tax

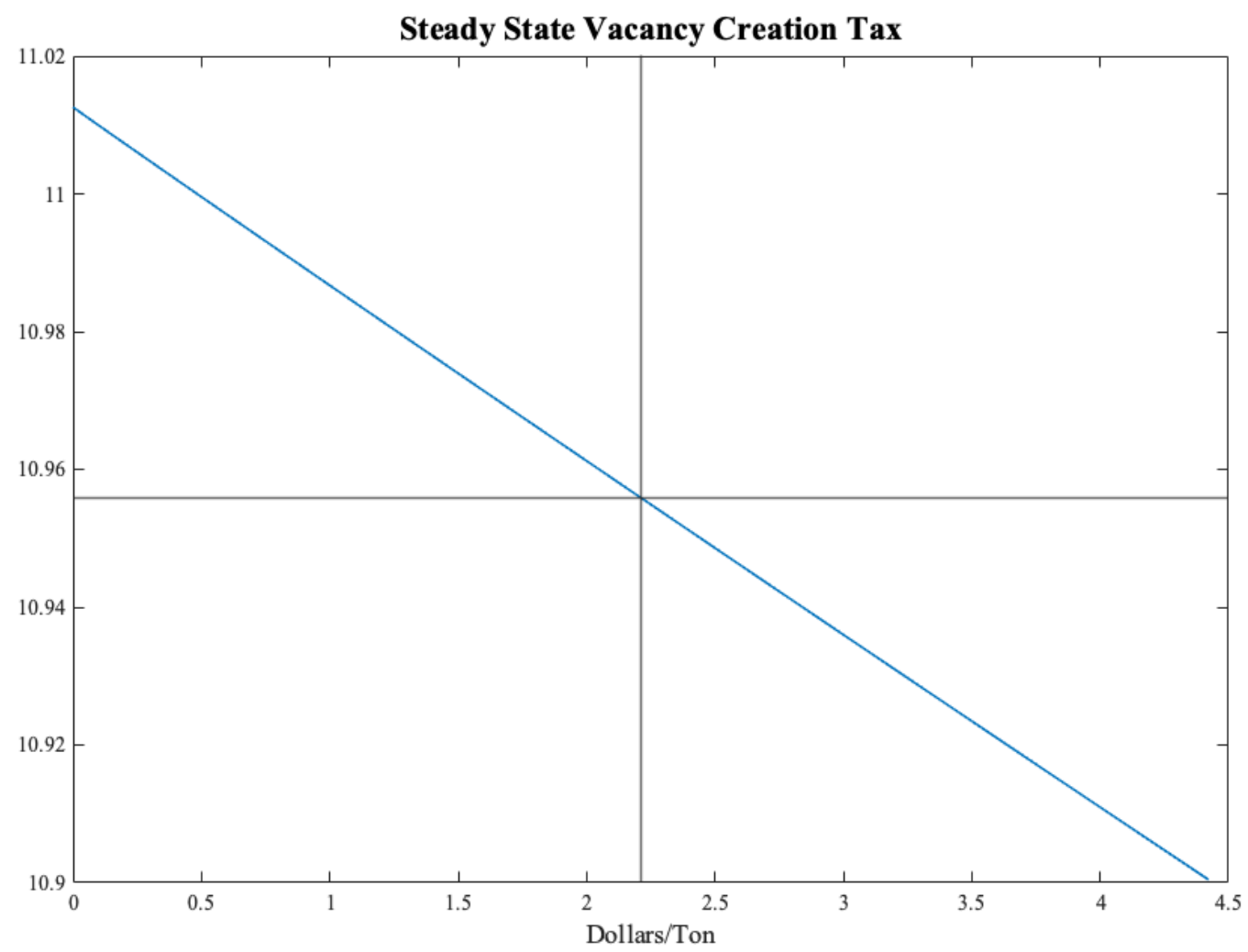

Notes: This figure is generated by solving for the (second-best) optimal vacancy creation tax while varying the emissions tax from 0 to twice its (first-best) optimal level. 
Figure 5: Impulse Response Functions - First- vs Second-Best Taxes

\section{Emissions Tax}
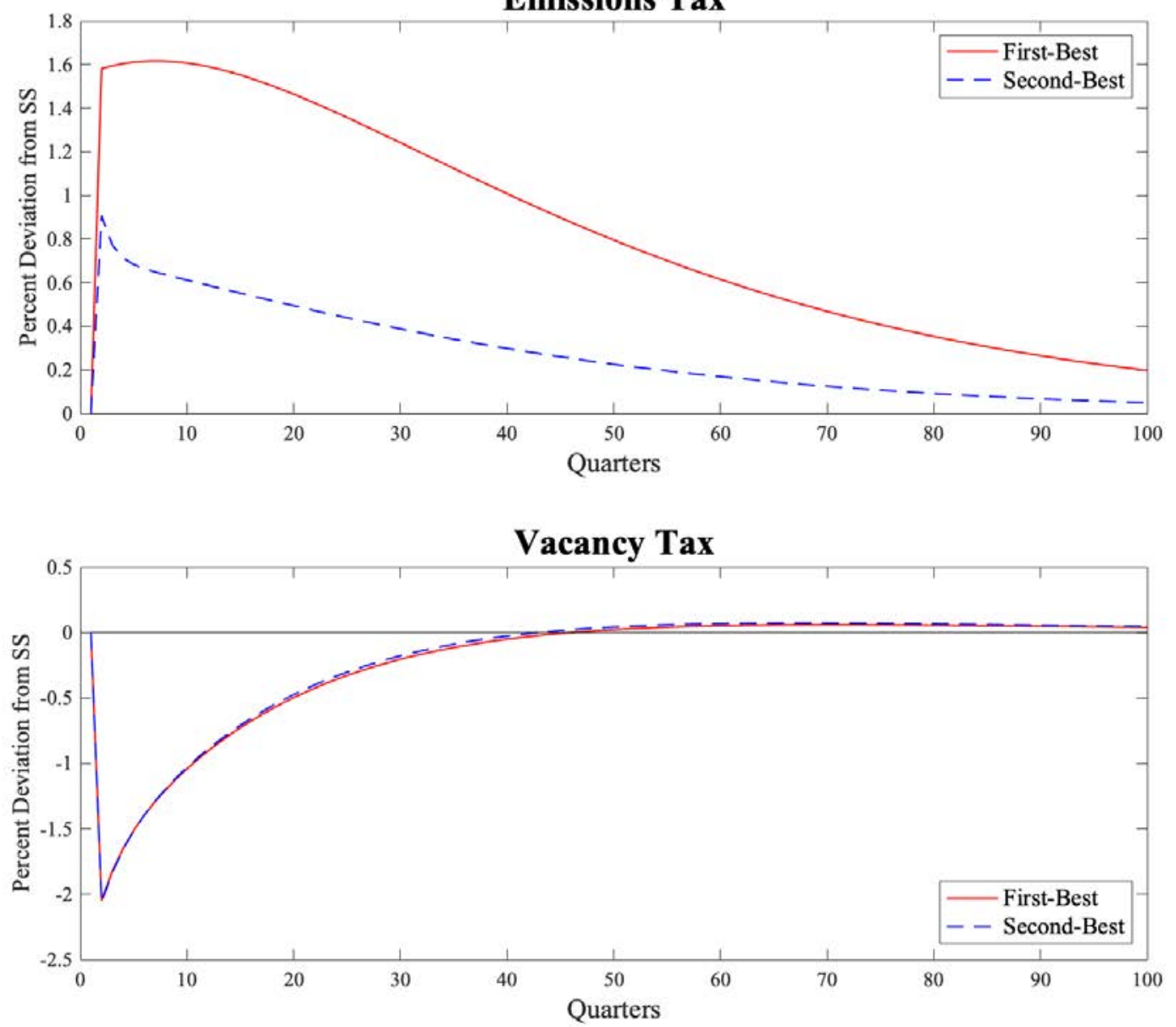

Notes: All simulations are from a one-unit one-time productivity innovation. 


\title{
Technical Appendix: Pollution and Labor Market Search Externalities Over the Business Cycle
}

\author{
John Gibson and Garth Heutel
}

In this appendix we provide additional details of the analytical model and planner's and Ramsey tax sub-problems from our DSGE model. We also provide additional details regarding our calibration, and we highlight additional results, including discussions regarding transitional dynamics, sensitivity analysis, and alternative welfare criteria.

\section{A More Details of Analytical Model}

Let $J$ equal the present discounted value of expected profit from an occupied job, and $V$ equal the present discounted value of expected profit from a vacant job. In equilibrium the Bellman equation for the asset value of a vacancy is $r V=-p(1-d) c+q(\Phi(J+p(1-d) H-V)$, where the left-hand-side is the capital cost (with exogenous discount rate $r$ ) and the righthand-side is the rate of return on the vacancy. In equilibrium, there are no rents from vacant jobs so $V=0$. The asset value of an occupied job is $r J=p(1-d)+a-w-s J$, where $w$ is the wage. Solving these yields the job creation condition:

$$
p(1-d)-w+a+p(1-d)(r+s)\left[H-\frac{c}{q(\Phi)}\right]=0
$$

Let $U$ equal the present discounted value of expected income of an unemployed worker, and $W$ equal the present discounted value of expected income of an employed worker. The asset value of being unemployed is given by $r U=z+\Phi q(\Phi)(W-U)$, where $z$ is the return to the worker during job search, for example the value of leisure. The asset value of a job for a worker is given by $r W=w+s(U-W)$.

The equilibrium wage is determined through Nash bargaining, where $b$ is the bargaining power of the worker. The wage maximizes $(W-U)^{b}(J+p(1-d) H-V)^{1-b}$, since $W-U$ is the surplus from a match going to the worker and $J+p(1-d) H-V$ is the surplus going to the firm. Substituting in and solving yields the wage equation:

$$
w=(1-b) z+b[(1+c \Phi+(r+s) H) p(1-d)+a]
$$

The social welfare function that the social planner seeks to maximize is

$$
\Omega=\int_{0}^{\infty} e^{-r t}[p(1-d(u))(1-u)+z u-p(1-d(u)) c \theta u] d t
$$

and the social planner is constrained by the unemployment evolution equation $\dot{u}=s(1-$ $u)-\Phi q(\Phi) u$. The social planner's choice variables are unemployment $u$ and labor market 
tightness $\Phi$, and let the co-state variable be $\mu$. The Euler conditions are

$$
\begin{gathered}
-e^{-r t}\left[p(1-d(u))-z+p(1-d(u)) c \Phi+d^{\prime}(u)(p(1-u)+p c \Phi u)\right]+[s+\Phi q(\Phi)] \mu-\dot{\mu}=0 \\
-e^{-r t} p c u(1-d(u))+\mu u q(\Phi)[1-\eta(\Phi)]=0
\end{gathered}
$$

Use equation A.5 to solve for $\mu$, take its time derivative $\dot{\mu}$, and substitute both into equation A.4. This yields equation 3 in the text.

Our model is similar to the models in Hafstead and Williams (2018) and Aubert and Chiroleu-Assouline (2019), both of which model labor market search frictions alongside a pollution externality. Like this model, neither of those papers' models consider productivity shocks or business cycles, though our paper's DSGE model considers them. More importantly, neither Hafstead and Williams (2018) nor Aubert and Chiroleu-Assouline (2019) consider Pigouvian pricing policies to minimize the inefficiencies from the two sources of market failure. Instead, both study the effect of exogenous (not optimized) pollution policy on labor markets, and neither consider policies to target the labor search externalities. However, these other papers include features absent from our paper, including two productive sectors (one polluting and one non-polluting) in Hafstead and Williams (2018), and heterogeneous workers (low-skill and high-skill) in Aubert and Chiroleu-Assouline (2019). Aubert and Chiroleu-Assouline (2019) demonstrate the importance of the Hosios condition on the distributional effects of a pollution tax; see their equation 17.

\section{B Planner's Problem}

The social planner chooses consumption, capital investment, vacancy creation, and the amount of emissions to abate, in order to maximize the representative household's present discounted value of expected life-time utility. The planner enters each period with a predetermined quantity of employed workers, capital, pollution, and knowledge of the current aggregate productivity in the economy. The optimization problem is constrained by an aggregate resource constraint and the aggregate evolution of employment in the economy and can be written as the following dynamic program:

$$
V\left(k_{t}, n_{t}, x_{t} ; \theta_{t}\right)=\max _{c_{t}, v_{t}, k_{t+1}, x_{t+1}}\left[\ln c_{t}-\xi n_{t}+\beta E\left\{V\left(k_{t+1}, n_{t+1}, x_{t+1} ; \theta_{t+1}\right)\right\}\right]
$$

s.t.

$$
\begin{aligned}
& c_{t}+k_{t+1}-(1-\delta) k_{t}+v_{t} G \leq\left(1-g\left(\mu_{t}\right)\right)\left[1-d\left(x_{t+1}\right)\right] \theta_{t} k_{t}^{\alpha} n_{t}^{1-\alpha} \\
& n_{t+1}=(1-s) n_{t}+\gamma\left(1-n_{t}\right)^{\gamma_{2}} v_{t}^{1-\gamma_{2}}
\end{aligned}
$$

where, from equations (9) and (11):

$$
\mu_{t}=1-\left[x_{t+1}-\lambda x_{t}-e_{t}^{\mathrm{row}}\right] \cdot h\left(\left(1-d\left(x_{t+1}\right)\right) \theta_{t} k_{t}^{\alpha} n_{t}^{1-\alpha}\right)
$$


Equation (B.1) denotes the economy's aggregate resource constraint. The first two terms on the left-hand side denote consumption expenditures and the capital investment. The third term on the left-hand side is the economy's expenditures on vacancy creation, with $G$ denoting per-vacancy posting cost, and the right-hand side denotes the total output less abatement.

Solving this problem yields the following three dynamic Euler equations:

$$
\begin{aligned}
& \beta E\left\{V_{k_{t+1}}\right\}=\frac{1}{c_{t}} \\
& \beta E\left\{V_{x_{t+1}}\right\}=\frac{1}{c_{t}}\left[-\left(1-g\left(\mu_{t}\right)\right) d^{\prime}\left(x_{t}\right) \theta k_{t}^{\alpha} n_{t}^{1-\alpha}+Y_{t} g^{\prime}\left(\mu_{t}\right)\left[\frac{h\left(Y_{t}\right)+e_{t} h^{\prime}\left(Y_{t}\right) d^{\prime}\left(x_{t}\right) \theta_{t} k_{t}^{\alpha} n_{t}^{1-\alpha}}{h\left(Y_{t}\right)^{2}}\right]\right] \\
& \beta E\left\{V_{n_{t+1}}\right\}=\frac{1}{c_{t}}\left[\frac{G}{\gamma_{1}\left(1-\gamma_{2}\right) \Phi_{t}^{-\gamma_{2}}}\right]
\end{aligned}
$$

where,

$$
\begin{aligned}
V_{k_{t+1}}= & \frac{1}{c_{t+1}}\left(1-d\left(x_{t+1}\right)\right) \theta_{t+1} \alpha\left(\frac{k_{t+1}}{n_{t+1}}\right)^{\alpha-1}\left[1-g\left(\mu_{t+1}\right)-Y_{t+1} g^{\prime}\left(\mu_{t+1}\right)\left(\frac{1-\mu_{t+1}}{h\left(Y_{t+1}\right)}\right) h^{\prime}\left(Y_{t+1}\right)\right] \\
& +\frac{1}{c_{t+1}}(1-\delta) \\
V_{x_{t+1}}= & \frac{1}{c_{t+1}} g^{\prime}\left(\mu_{t+1}\right) Y_{t+1} \frac{\lambda}{h\left(Y_{t+1}\right)} \\
V_{n_{t+1}}= & \frac{1}{c_{t+1}}\left(1-d\left(x_{t+1}\right)\right) \theta_{t+1}(1-\alpha)\left(\frac{k_{t+1}}{n_{t+1}}\right)^{\alpha}\left[1-g\left(\mu_{t+1}\right)-g^{\prime}\left(\mu_{t+1}\right) Y_{t+1}\left[\frac{1-\mu_{t+1}}{h\left(Y_{t+1}\right)}\right] h^{\prime}\left(Y_{t+1}\right)\right] \\
& -\xi+\frac{1}{c_{t+1}}\left[\frac{1-s-\gamma_{1} \gamma_{2} \Phi_{t+1}^{1-\gamma_{2}}}{\gamma_{1}\left(1-\gamma_{2}\right) \Phi_{t+1}^{-\gamma_{2}}}\right] G
\end{aligned}
$$

Equation B.4 is the dynamic Euler on capital accumulation, while equation B.5 is the dynamic Euler on emissions and pollution. Equations similar to (B.4) and (B.5) appear in Heutel (2012); here they depend on the current and future levels of employment in the economy. Equation B.6 is unique to our model and defines the planner's vacancy creation condition. Inspection of equations B.4. B.6 and the corresponding envelope conditions show that there is a feedback relationship between emissions and employment, with the current and future emissions impacting vacancy creation and current and future employment impacting the emissions decision.

\section{Ramsey Efficient Dynamic Tax Problem}

The Ramsey optimal dynamic tax problem for a model economy can be written as the following constrained optimization: 


$$
\begin{aligned}
& \max _{\left\{c_{t}, k_{t+1}, n_{t+1}, x_{t+1}, v_{t}, r_{t}, w_{t}, \mu_{t}, q_{t}, Y_{t}, \text { and } \tau_{e_{t}} \text { or } \tau_{v_{t}} \text { (or both }\right\}_{t=0}^{\infty} \sum_{t=0}^{\infty} \beta^{t}\left[\ln c_{t}-\xi n_{t}\right]} \\
& \text { s.t., for all } t \\
& \beta E_{t}\left\{\left(\frac{1}{c_{t+1}}\right)\left[r_{t+1}+1-\delta\right]\right\}=\frac{1}{c_{t}} \\
& r_{t}=\alpha\left(1-d\left(x_{t+1}\right)\right) \theta_{t}\left(\frac{k_{t}}{n_{t}}\right)^{\alpha-1}\left[1-g\left(\mu_{t}\right)-\tau_{e_{t}}\left(1-\mu_{t}\right) h^{\prime}\left(Y_{t}\right)\right] \\
& \beta E_{t}\left\{\frac{c_{t}}{c_{t+1}}\left[\left(\frac{1-\alpha}{\alpha}\right) r_{t+1}\left(\frac{k_{t+1}}{n_{t+1}}\right)-w_{t+1}+(1-s) \frac{\left(1+\tau_{v_{t+1}}\right) G}{q_{t+1}}\right]\right\}=\frac{\left(1+\tau_{v_{t}}\right) G}{q_{t}} \\
& \tau_{e_{t}} h\left(Y_{t}\right)=g^{\prime}\left(\mu_{t}\right) Y_{t} \\
& N_{t+1}=(1-s) N_{t}+v_{t} q_{t} \\
& w_{t}=(1-b) \xi c_{t}+b\left[\left(\frac{1-\alpha}{\alpha}\right) r_{t}\left(\frac{k_{t}}{n_{t}}\right)+\left(\frac{v_{t}}{1-n_{t}}\right)\left(1+\tau_{v_{t}}\right) G\right] \\
& c_{t}+k_{t+1}-(1-\delta) k_{t}+v_{t} G=\left(1-g\left(\mu_{t}\right)\right) Y_{t} \\
& x_{t+1}=\lambda x_{t}+\left(1-\mu_{t}\right) h\left(Y_{t}\right)+e^{\mathrm{ROW}} \\
& Y_{t}=\left(1-d\left(x_{t+1}\right)\right) \theta_{t} k_{t}^{\alpha} n_{t}^{1-\alpha} \\
& q_{t}=\gamma_{1}\left(1-n_{t}\right)^{\gamma_{2}} v_{t}^{-\gamma_{2}}
\end{aligned}
$$

This system has been simplified using equations 11 and 12 from the main paper to rewrite $e_{t}$ and $z_{t}$ as functions of $\mu_{t}$ and $Y_{t}$. All remaining endogenous variables are chosen by the government in order to maximize the representative household's present discounted value of expected life-time utility, taking as constraints the equations from the decentralized problem. Notice that when we specify the government's choice variables we list $\left\{\tau_{e_{t}}\right\}_{t=0}^{\infty}$ or $\left\{\tau_{v_{t}}\right\}_{t=0}^{\infty}$ (or both), indicating that we will consider the following three scenarios: (i) the government recovers the first-best allocation by optimally choosing both $\left\{\tau_{e_{t}}\right\}_{t=0}^{\infty}$ and $\left\{\tau_{v_{t}}\right\}_{t=0}^{\infty}$; (ii) the government recovers a second-best allocation by optimally choosing $\left\{\tau_{e_{t}}\right\}_{t=0}^{\infty}$, with $\tau_{v_{t}}$ held fixed; (iii) the government recovers a second best allocation by optimally choosing $\left\{\tau_{v_{t}}\right\}_{t=0}^{\infty}$, with $\tau_{e_{t}}$ held fixed.

\section{Additional Calibration Details}

\section{D.1 Emissions Elasticity Calibration}

We calibrate the relationship between emissions and output, $e_{t}=h\left(y_{t}\right)=y_{t}^{1-\gamma}$, using monthly data on U.S. carbon dioxide emissions and GDP. The monthly emissions data come from the Energy Information Administration, and they include carbon dioxide emis- 
sions from all sources of energy consumption from January 1981 through October 2019.29 For most specifications, we use data that are first seasonally adjusted, using the Census Bureau's X-13ARIMA-SEATS seasonal adjustment program.30 Monthly estimates of GDP are from the dataset provided by Jarociński and Karadi (2020) 31

Figure D.1 plots the monthly emissions data alongside the monthly GDP estimates. Business cycles are apparent in the GDP series, including the Great Recession starting in 2007. The seasonally-adjusted emissions data are noisier, but it appears to be the case that when GDP falls, so do emissions. The long-run trend of the carbon intensity of the economy decreasing is apparent, especially starting after the Great Recession.

Figure D.2 plots the cyclical components of the GDP and emissions series. The data are detrended using the Hodrick-Prescott filter after being aggregated to the quarterly level. The smoothness parameter used in the filtering is $\lambda=1600$. As with the plot of the levels in Figure D.1, the cyclical components plotted in Figure D.2 demonstrate the correlation between output and emissions. During recessions, emissions fall, and during expansions, emissions rise.

We turn to regression analysis to quantify the cyclical correlation between emissions and GDP. Table D.1 presents the regression results. Each column is a different specification, though all columns represent regressions where the dependent variable is the natural log of the cyclical component of emissions and the independent variable of interest is the natural log of the cyclical component of GDP. Thus the reported coefficients are estimates of the elasticity parameter $1-\gamma$. The first two columns are ARIMA regressions, while the remaining four columns are least squares regressions of data that have been detrended.

Column 1 presents a seasonal $\operatorname{ARIMA}(1,1,1) \times(0,1,1)_{12}$ regression, where the left-handside emissions data have not been seasonally adjusted outside of the regression. Column 2 presents an $\operatorname{ARIMA}(1,1,2)$ regression, where the left-hand-side emissions data are seasonally adjusted using the Census X-13 program before the regressions. In all subsequent columns, the emissions data are seasonally adjusted this way before running the regressions. Columns 3 through 6 present regressions using different detrending algorithms. Column 3's regressions use the Hodrick-Prescott filter, column 4's use Baxter-King, column 5's use ChristianoFitzgerald, and column 6's use Butterworth ${ }^{32}$

In all regressions, we see a positive coefficient on emissions, indicating a procyclical relationship between emissions and output. This verifies what we can see in Figures D.1 and D.2. The value of the coefficient ranges between 0.48 and 0.93 , less than 1 , indicating that emissions are relatively inelastic to output. Because of the range of estimated parameters, we choose an intermediate value of 0.6 to use in the simulations, consistent with the result found in Cohen et al. (2018).

\footnotetext{
${ }^{29}$ Data are available here: https://www.eia.gov/totalenergy/data/monthly/\#environment.

${ }^{30}$ Details of this program are available here: https://www.census.gov/srd/www/x13as/, The seasonal adjustment is performed using the EViews software.

${ }^{31}$ These data are available here: https://www. aeaweb.org/doi/10.1257/mac.20180090.data. Interpolating GDP to a monthly frequency is based on the methodology described in Stock and Watson (2000).

${ }^{32}$ These specifications parallel those reported in Heutel (2012), though here we use more recent data.
} 
Figure D.1: Carbon Dioxide Emissions and GDP

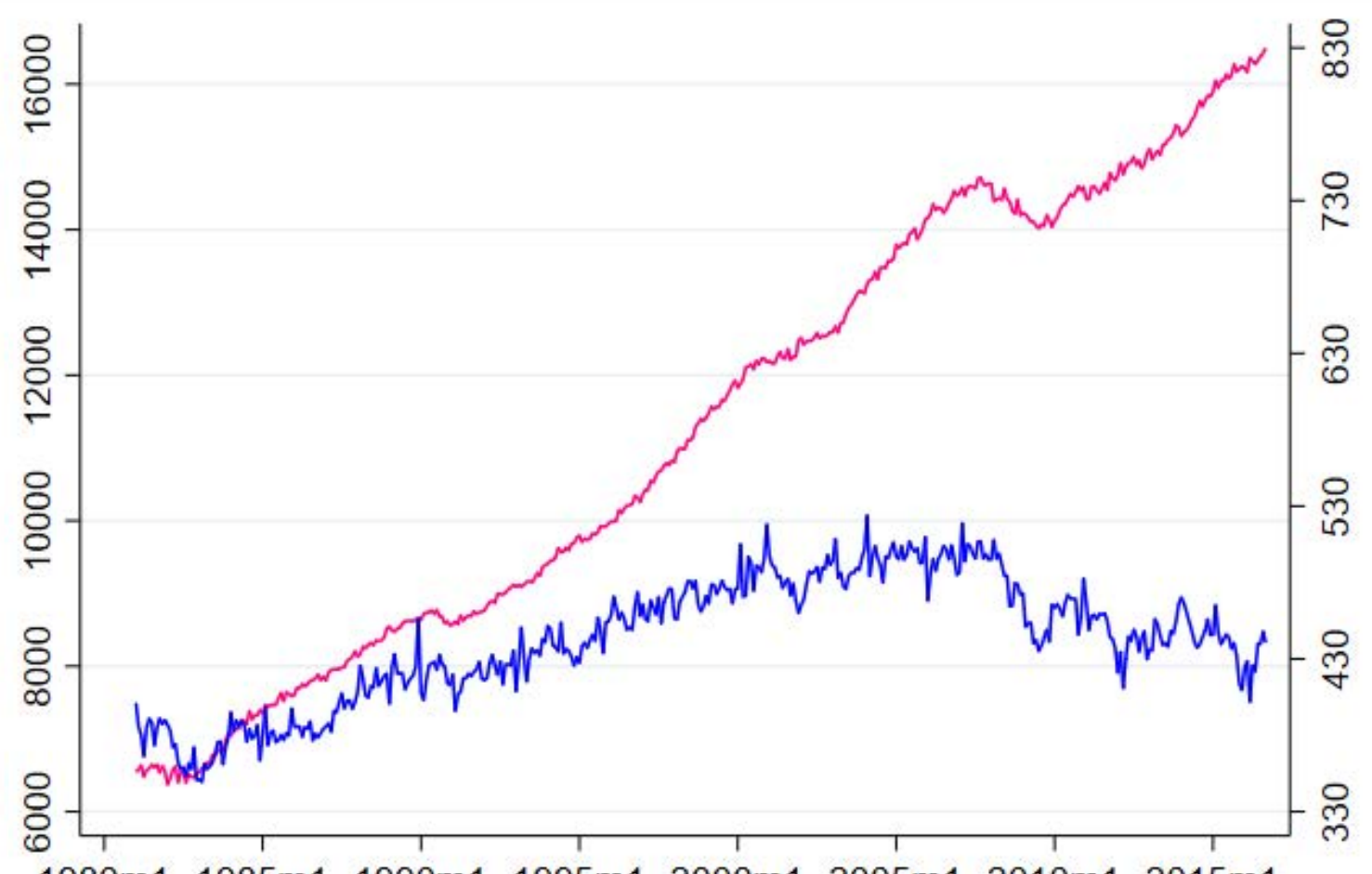

1980m1 1985m1 1990m1 1995m1 2000m1 2005m1 2010m1 2015m1

$$
\text { GDP CO2 Emissions }
$$


Figure D.2: Carbon Dioxide Emissions and GDP, Cyclical Components

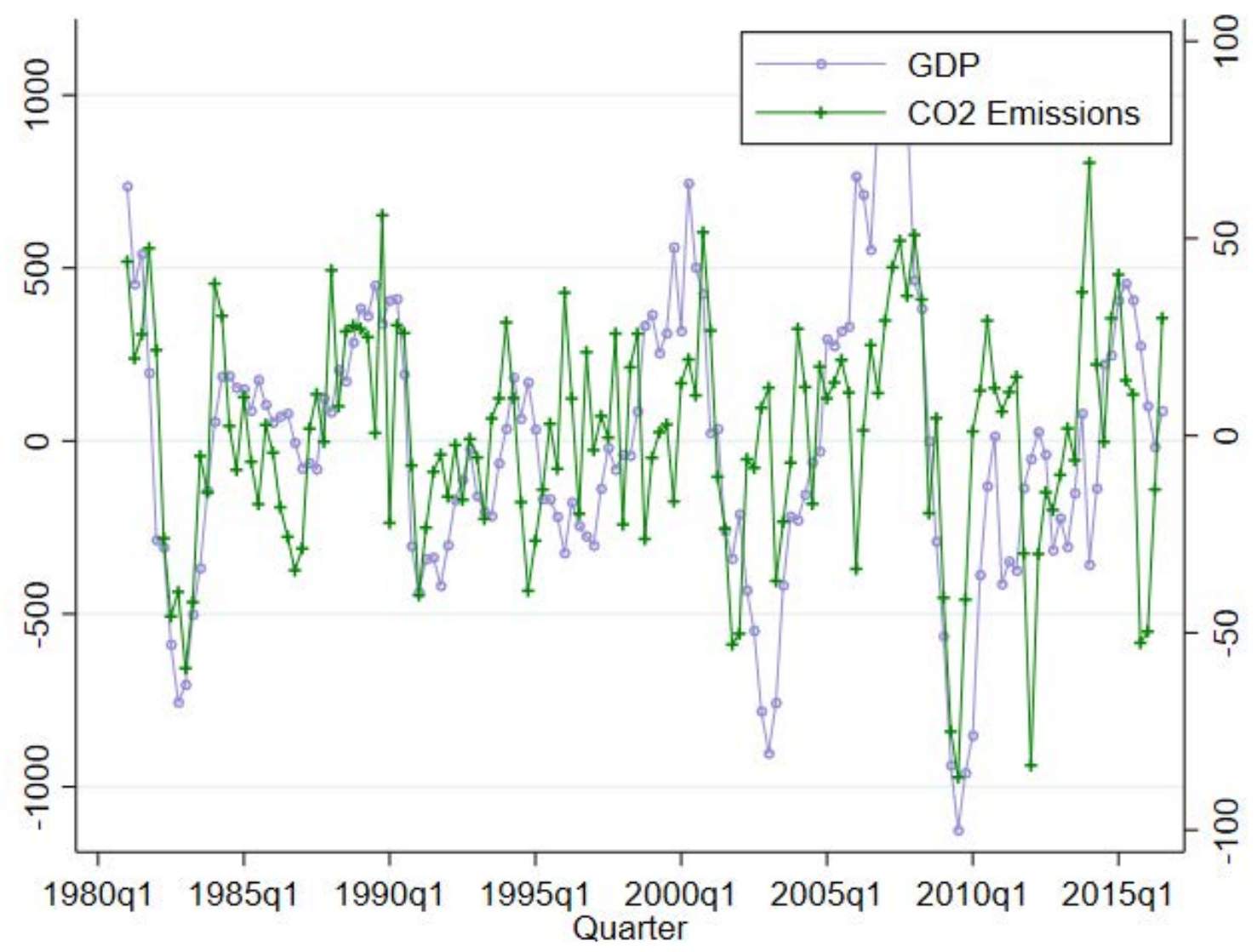




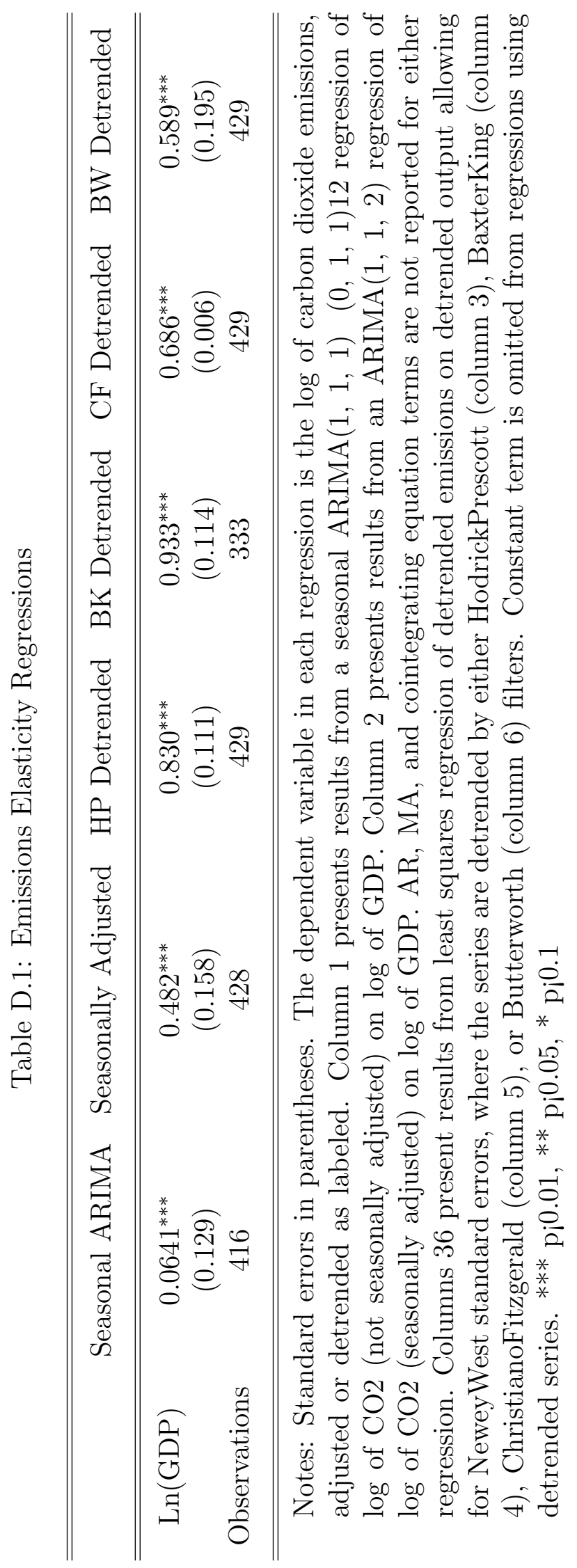




\section{D.2 Damage Function Calibration}

We calibrate the damage function $d(x)$, where $x$ is the stock of carbon pollution in the atmosphere, and $d$ is damages expressed as a fraction of gross output (so that net output equals gross output times $1-d$ ). The calibration methodology is identical to that of Heutel (2012), though here we use the most updated version of the DICE model.

The calibration is as follows. We begin with a fixed, exogenous level of the atmospheric carbon stock, in GtC. For that fixed level, we run the climate model portion of DICE, in which the atmospheric carbon stock interacts over time with the ocean carbon stock, affects radiative forcing, and ultimately affects temperature. For a given temperature, the DICE model provides parameters for a damage function (which is quadratic in temperature). For the fixed, exogenous level of the atmospheric carbon stock, we run the climate model for 20 periods (100 years), and calculate temperature and thus climate damages in each period. We take a simple average of the climate damages over those 20 periods, and assign that damage fraction to be the damage associated with the given fixed, exogenous level of atmospheric carbon stock.

We perform this simulation for 100 different values of this fixed, exogenous level of atmospheric carbon stock, ranging from 800 to 1600 GtC. The relationship between the carbon stock and damages is presented in Figure D.3. We fit these points to a quadratic function of the carbon stock, yielding the damage function $d(x)=d_{2} x^{2}+d_{1} x+d_{0}$, where $d_{2}=1.05 e-8$, $d_{1}=8.10 e-6$, and $d_{0}=-0.0076$. The units of the carbon stock $x$ in this calibrated function are GtC, while the units of the variable in our DSGE model are arbitrary. Therefore, in our code we re-scale our carbon stock variable to be consistent with the calibration. We set the steady-state-level of the carbon stock $x$ to equal the current (as of DICE 2016R2) atmospheric carbon stock, 851 GtC.

\section{D.3 Labor Market Parameters}

Several calibration strategies exist for models with DMP search frictions, with the primary difference being how vacancy postings costs, $G$, the disutility of work, $\xi$, and worker's bargaining power, $b$, are determined. Shimer (2005) presents a calibration strategy where $\xi$ is set to target the replacement rate of unemployment insurance for the U.S. (approximately $40 \%$ ) and worker's bargaining power is set equal to the elasticity of matches with respect to unemployment following Hosios (1990), the so-called Hosios condition. The flow cost of vacancy creation, $G$, is not explicitly targeted under this strategy, but is instead left free to adjust so the model can reach other desired targets. Such a calibration strategy is not suitable for our purposes as it implicitly shuts down one of our primary channels of interest, the inefficient level of vacancy creation by firms in the decentralized economy. Specifically, adopting the Hosios condition in calibration is a well-known strategy for internalizing congestion externalities and achieving the first-best allocation within a decentralized labor market search model. As such, under this calibration firms in the decentralized economy will create the socially efficient level of vacancies.

Fortunately, another popular calibration scheme proposed by Hagedorn and Manovskii 
Figure D.3: Damage Function Calibration

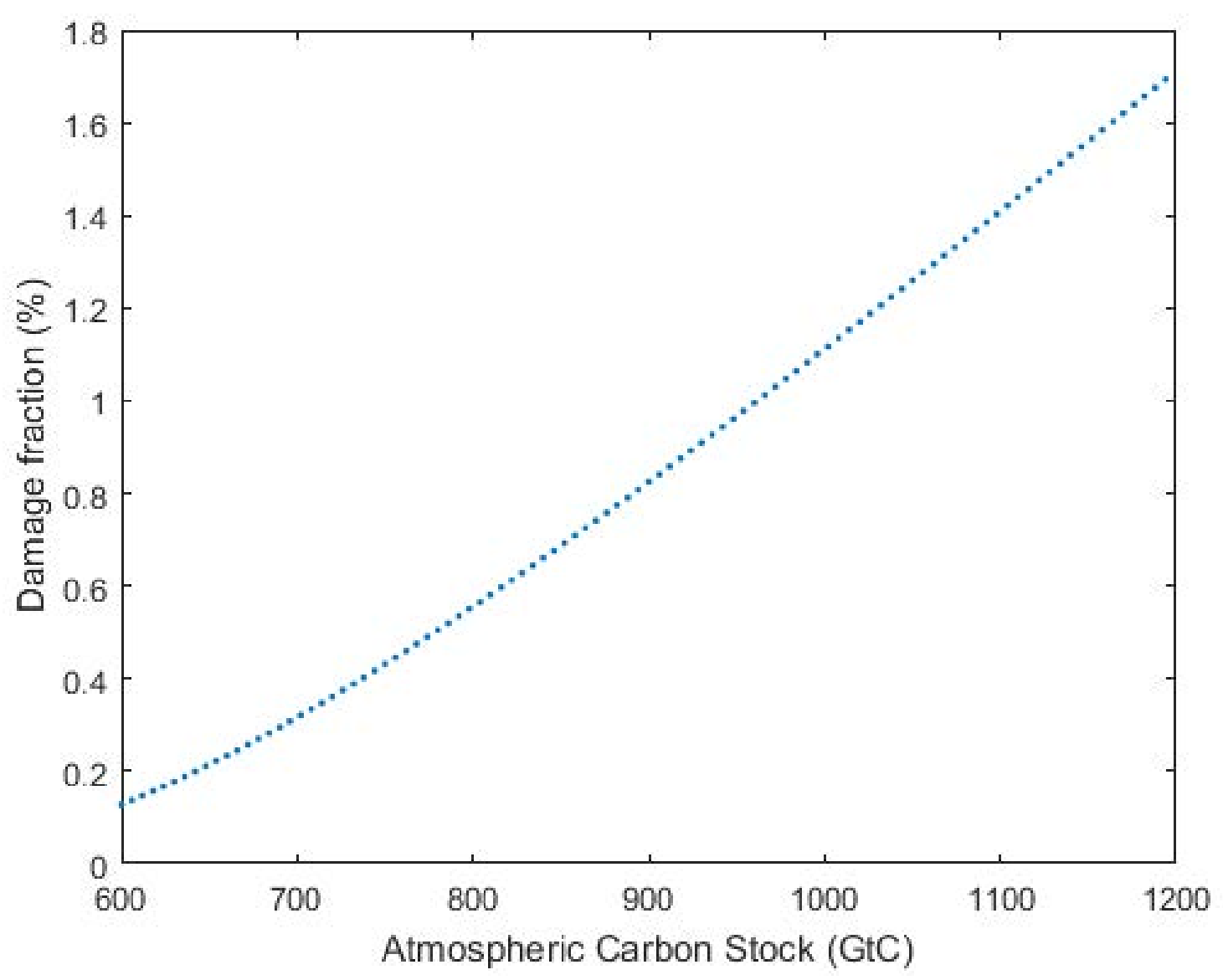

(2008) does not impose the Hosios condition. Instead of determining vacancy costs as a residual of the calibration exercise, the authors target this value directly. The authors state that vacancy costs are significantly lower in the data and, as such, they set $G$ to match their empirical target. Furthermore, workers' bargaining power is set to target the elasticity of wages with respect to average labor productivity observed in the data. This alternative calibration strategy results in a small match surplus that varies significantly at business cycle frequencies and has been shown to generate empirically realistic volatility in labor market variables.

Setting $b=0.05$ results in an elasticity of wages with respect to average labor productivity of 0.546 . While this is larger than the target of 0.449 reported in Hagedorn and Manovskii (2008), this outcome is not unexpected. One reason for this difference is that we are working with an RBC search model which adopts a more conventional utility function that assumes agents are risk averse. In contrast, Hagedorn and Manovskii (2008) present their results using a traditional DMP search model with risk neutral agents. See Atolia et al. (2018) for 
a more thorough discussion on this issue.

\section{E Additional Results}

\section{E.1 Decentralized Problem}

Figure E.1 presents three panels of impulse response functions recovered from the unregulated decentralized economy. The first panel shows the response of output, consumption, and investment to a one-time, one-standard deviation innovation in total factor productivity. For scale, the impulse response function for productivity is also included. The second and third panels of Figure E.1 show the response for labor market and environmental variables, respectively. As described in the main text, the response of these variables is consistent with existing literature and serve to highlight the relatively high volatility of labor market variables in the decentralized economy and the fact that firms do not abate emissions in absence of corrective policies (e.g., an emissions tax).

Figure E.2 presents the 100-period stochastic time paths recovered from the baseline decentralized economy. Just as before, the top panel present the time paths for traditional real business cycle variables along with total factor productivity, and the second and third panels present the time paths for labor market and environmental variables.

\section{E.2 Planner's Problem}

Figures E.3 and E.4 present impulse response functions and time paths for the planner's problem. These figures are ordered in the same way as Figures E.1 and E.2 described above. The primary difference is the volatility in the fraction of emissions abated and the amount of resources (output) devoted to abatement spending in the planner's problem. Comparsions of the labor market plots also reveal differences in the volatiity of labor market variables across model specifications.

\section{E.3 Ramsey Efficient Dynamic Tax Problem}

Figures E.5 and E.6 present time paths of the first-best and second-best Ramsey taxes, respectively.

\section{F Transition Dynamics}

Here we present simulations of the transitions from one steady-state equilibrium to another. In particular, we run several simulations that all start at the steady state under the unregulated decentralized economy and have no TFP shocks. One simulation is the decentralized model without policy; under this simulation all variables simply remain at their steady-state values for all periods. Three other simulations employ the first-best emissions and vacancy 
taxes, the second-best emissions tax, and the second-best vacancy tax, respectively. In Figure F.1, we present the levels of consumption, employment, and utility for each of the first 100 periods under each simulation.

As described in the text, when conducting welfare analysis by calculating compensating variation, rather than just comparing steady states across policies, we start all simulations at the same initial state and simulate the transition to the new steady state. If we just compared steady state welfare, we find that the steady-state welfare under the second-best vacancy tax is actually slightly higher than the steady-state welfare under the first-best taxes. The difference is so slight that it is difficult to see in the bottom panel of Figure F.1 towards the end of the simulation as the steady state is approached. However, it is clear to see that through most periods of the transition, the first-best utility is higher than that of the second-best emissions tax, which is higher than that of the decentralized equilibrium. If instead we conducted welfare analysis by merely comparing welfare under the different steady states, this would not be an apples-to-apples comparison. The state variables, in particular pollution and employment, are drastically different across policies, so just comparing steady states amounts to unfairly starting the simulations at different points.

Figure F.1 also clearly demonstrates that the second-best vacancy tax brings about an outcome much closer to the first best than does the second-best emissions tax. In Figure F.1, the curves for the first best and the second-best vacancy tax are almost coincidental, while the second-best emissions tax is noticeably different. Under the second-best emissions tax, consumption is substantially higher than in the first best (which increases utility), but employment is also substantially higher (which reduces utility).

\section{G Sensitivity Analysis}

We consider how sensitive the results are to our calibrated parameter values. In particular, we focus on the set of parameters that lead to the externalities. The magnitude of the labor market search externalities are governed by the parameters from the Hosios condition - the worker's bargaining power $b$ and the elasticity of the matching function $\gamma_{2}$. The magnitude of the pollution externality is governed by the damage function $d(x)$. We vary bargaining power $b$, because that is a parameter that is known with much less confidence than many of the others, while we keep the matching elasticity $\gamma_{2}$ fixed at its base-case level. We also vary the damage function by adding a scale parameter in front of $d(x)$ that increases or decreases it by a fixed fraction.

The sensitivity analysis results are presented in Figures G.1 and G.2. In Figure G.1. we present results for the first-best emissions and vacancy taxes under different parameter values. The left two panels show how the two taxes vary with the bargaining parameter $b$, and the right two panels show how they vary with pollution damages $d(x)$. As we vary bargaining power from 0 , where workers receive none of the match surplus, to 1 , where workers receive all of it, the first-best emissions tax barely changes (it only changes at the 13 th decimal place). The vacancy tax decreases as $b$ increases, reflecting the fact from the efficient tax expression in equation 4 that the magnitude of the net congestion externality 
is proportional to $b-\gamma_{2}$, as in the Hosios condition. When $b$ just equals $\gamma_{2}$, which is 0.72 , then the efficient vacancy tax is zero. When $b$ is greater than $\gamma_{2}$, then the efficient vacancy tax becomes negative, i.e. a vacancy subsidy, since the direction of the externality flips. The upper-right panel shows that as the damages from pollution increase, the efficient emissions tax increases also. This reflects the efficient Pigouvian tax in equation 5. The lower-right panel shows that the vacancy tax slightly decreases as the damages from pollution increases, again reflecting the interaction between the two policies discussed in the analytical model and reflected in equation 4. Even when varying these parameters, the scale of the first-best emissions tax stays quite low, never going higher than $\$ 7$ per ton, much lower than standard estimates of the social cost of carbon. In part this may be due to the calibration technique for the damage function (described in the appendix). But it also arises because of the labor market search costs reducing employment, and thus reducing output and emissions. Part of the work of the emissions tax is already being done by these search frictions.

In Figure G.2, we present results for the second-best emissions and vacancy taxes under different parameter values. As worker bargaining power increases from 0 to 1 , both the second-best emissions tax and the second-best vacancy tax decrease by a large amount. The second-best emissions tax decreases from over $\$ 100$ per ton to just single digits as $b$ increases from 0 to about 0.5 . The second-best vacancy tax becomes a subsidy when $b$ falls below $\gamma_{2}(0.72)$. When we vary emissions damages in the right-side panels, both the second-best emissions tax and the second-best vacancy tax vary, though they vary by a smaller amount. The scale of the second-best emissions tax is much higher than the first-best emissions tax, and in fact is higher than common estimates of the social cost of carbon. In the second best, the emissions tax must address both sets of externalities, so it is higher than in models with only the pollution externality 33

\section{H Equity Concerns and Alternate Welfare Criteria}

The welfare analyses of the preceding sections assume that the welfare criterion defining the first best considers only efficiency. Equity or distributional concerns are ignored. Also, in the preceding analyses the only cost of unemployment is the foregone production of the idle workforce. The analyses ignore the substantial psychological costs to the unemployed, costs to society that exceed the opportunity cost of idleness.

We consider two extensions to the numerical model that address these issues. First, we address equity concerns. Our model has one representative household and one representative firm, so the only distributional outcome we can examine is the differential outcomes between these two representatives (i.e. we cannot look at distributional outcomes across income or race) ${ }^{34}$ Furthermore, because the representative firm is owned by the representative

\footnotetext{
${ }^{33}$ This result is similar to the second-best emissions tax found in Barrage (2020), where distortions from pre-existing taxes, rather than another market failure, make the efficient tax differ from marginal external damages.

${ }^{34}$ Other DSGE models do incorporate heterogeneous agents, including Iacoviello (2005), Kaplan et al. (2018), and Hohberger et al. (2020).
} 
household, the delineation between these two agents is muddled. Nevertheless, we proceed by analyzing the difference in outcomes for the firm and for the worker to provide an initial assessment of distributional outcomes of our policies.

In Table H.1, we present the steady-state values of the household's utility, the firm's profit, and the unemployment rate, under several equilibrium outcomes. The first row presents these three values under the decentralized equilibrium with no policies $\left(\tau_{e}=\tau_{v}=0\right)$. The second row is from the planner's problem, which maximizes total welfare. The last three rows are from decentralized equilibria with non-zero policy values. The third row is with the first-best emissions and vacancy taxes; this row is equivalent to the planner's problem. The fourth and fifth rows are with the second-best emissions and vacancy taxes, respectively. The utility and profit values are in arbitrary units, so we also present these values as percentages of the first-best values (0.0642 for utility and 0.1220 for profit). Profit is undefined in the planner's problem since input prices are undefined. These calculations are based on just the steadystate equilibria under each of the policies and do not include the transition paths (which are explored in appendix section F.

Moving from the unregulated decentralized equilibrium to the first best only slightly increases household utility but increases firm profit by almost an order of magnitude. The unemployment rate nearly doubles. While total efficiency increases, the benefits accrue mainly to the firm. Though the household has slightly higher utility in the first best than in the unregulated equilibrium, the doubling of unemployment should not be ignored. In the model, holding consumption constant an increase in unemployment actually benefits the household since leisure increases. In the real world, this unemployment increase is bad for workers. Comparing the second-best emissions tax with the second-best vacancy tax shows that the latter is more efficient overall (both utility and profit nearly as high as their first-best levels), but the former is better for the household (higher utility and lower unemployment). This very back-of-the-envelope decomposition thus suggests a trade-off between efficiency and equity in policy design, pitting the more efficient policy (the vacancy tax) against the more equitable policy (the emissions tax).

Second, we consider the excess psychological costs of unemployment by employing alternate welfare criteria. A large literature documents the negative effect of unemployment on people, including reductions in self-reported life satisfaction (Kassenboehmer and HaiskenDeNew, 2009), decreases in mental health (Marcus, 2013), decreases in social participation (Kunze and Suppa, 2017), and increases in suicides (Classen and Dunn, 2012; Milner et al., 2013). The worker's single-period utility equals $\ln c_{t}-\xi n_{t}$, where $\xi$ represents the disutility of work. To capture the psychological costs, or disutility, from unemployment, we introduce an additional component to the utility function, $\kappa\left(1-n_{t}\right)$. The single-period utility is now $\ln c_{t}-\xi n_{t}-\kappa\left(1-n_{t}\right)$. In order to keep the equilibrium outcomes the same as their calibrated values in the decentralized case, we assume that the households behave according to the original utility function $\ln c_{t}-\xi n_{t}$. But the government sets policy so as to maximize utility inclusive of the unemployment disutility, $\ln c_{t}-\xi n_{t}-\kappa\left(1-n_{t}\right)$. This distinction between the utility function that describes the agent's behavior and the utility function that describes optimal or efficient outcomes is analogous to the distinction between decision 
Table H.1: Distributional Outcomes

\begin{tabular}{cccc}
\hline \hline & Household Utility & Firm Profit & Unemployment Rate \\
\hline Unregulated Decentralized & 0.0634 & 0.0149 & $7.87 \%$ \\
& $(99 \%)$ & $(12 \%)$ & \\
Planner's Problem & 0.0642 & N $/ \mathrm{A}$ & $13.74 \%$ \\
& $(100 \%)$ & & \\
First-Best Taxes & 0.0642 & 0.1220 & $13.74 \%$ \\
& $(100 \%)$ & $(100 \%)$ & \\
Second-Best Emissions Tax & 0.0675 & 0.0380 & $8.39 \%$ \\
& $(105 \%)$ & $(31 \%)$ & \\
Second-Best Vacancy Tax & 0.0635 & 0.1216 & $13.74 \%$ \\
& $(99 \%)$ & $(100 \%)$ & \\
\hline \hline
\end{tabular}

Notes: This table presents steady-state values for household utility, firm profit, and unemployment under five equilibrium scenarios under base-case parameter values. Household utility and firm profit are in arbitrary units; the percents in parentheses below these values are the percentage relative to the first best. Firm profit is undefined in the planner's problem since input prices are undefined. The representative household owns the representative firm and receives its profits as income.

utility and experienced utility often used in behavioral welfare economics (Kahneman and Sugden, 2005).

In Figure H.1, we present values for the first- and second-best steady-state emissions and vacancy taxes for different values of the unemployment disutility parameter $\kappa$, ranging from 0 to 0.6 . For comparison, the disutility of work parameter $\xi$ is 0.85 , so when $\kappa=0.425$, the unemployment disutility is half as high as the disutility of work. The first row shows that as unemployment disutility $\kappa$ gets higher, the first-best vacancy tax decreases by a lot and the first-best emissions tax increases by a little. When $\kappa=0.425$, the first-best vacancy tax is about an order of magnitude smaller than its base-case value when $\kappa=0$, while the first-best emissions tax is only about $10 \%$ greater than its base-case value. Even including disutility of unemployment with just a modest magnitude greatly reduces the tax on vacancies. The bottom row of Figure H.1 shows how the second-best taxes respond to $\kappa$. The second-best vacancy tax is almost identical to the first-best vacancy tax. But, the second-best emissions tax is much more responsive to $\kappa$ than is the first-best emissions tax. Increasing $\kappa$ from 0 to 0.425 decreases the second-best emissions tax by more than $50 \%$. This panel demonstrates an important trade-off between reducing emissions and avoiding adverse effects on workers. 
Figure E.1: Impulse Response Functions - Decentralized Problem

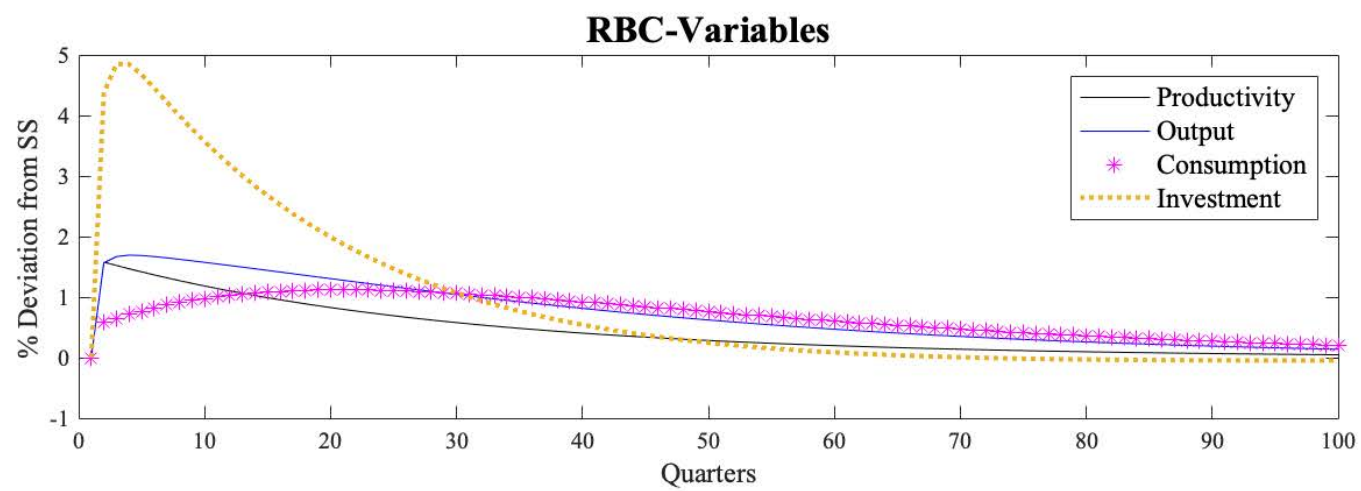

Labor Market Variables

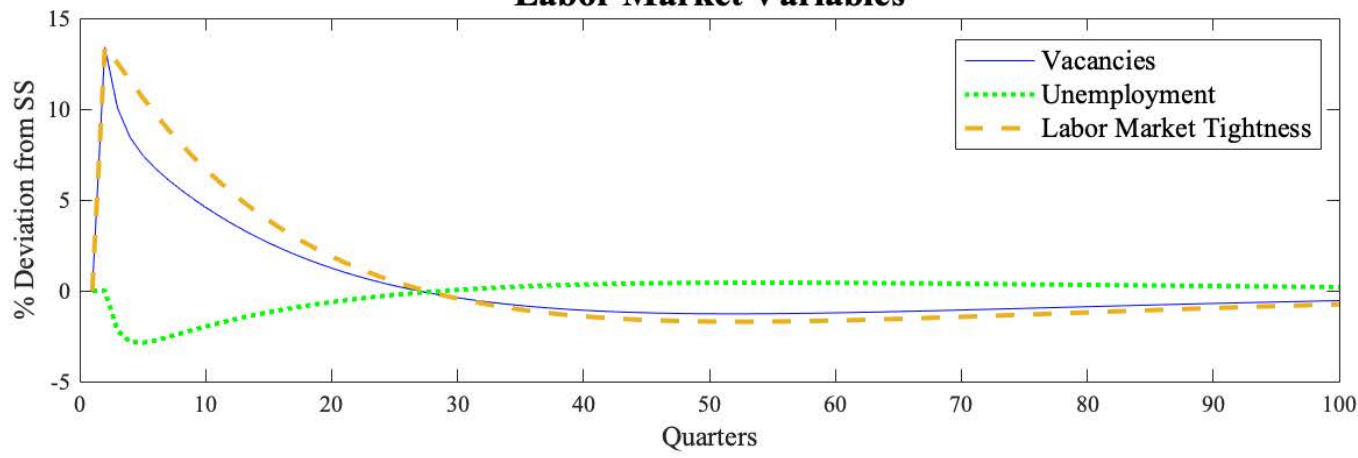

Environmental Variables

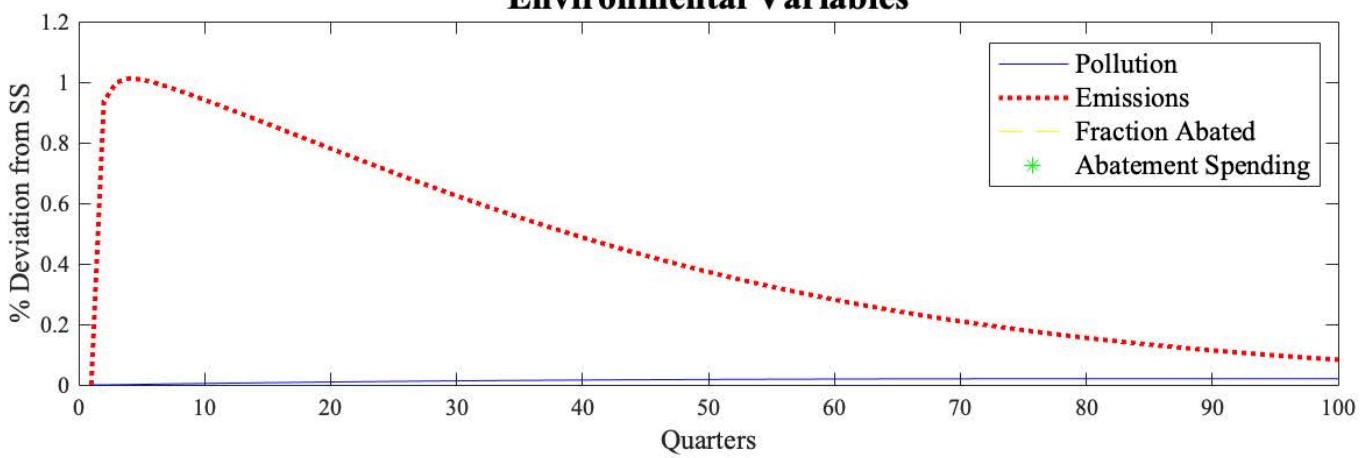

Notes: All simulations are from a one-unit one-time productivity innovation. 
Figure E.2: Business Cycle Simulations - Decentralized Problem

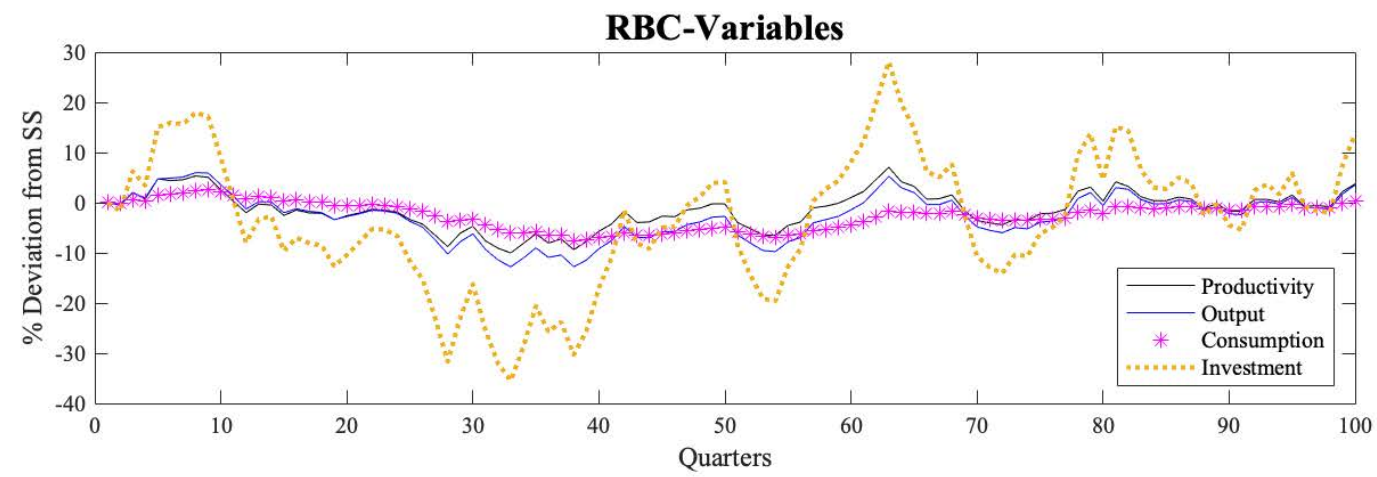

Labor Market Variables

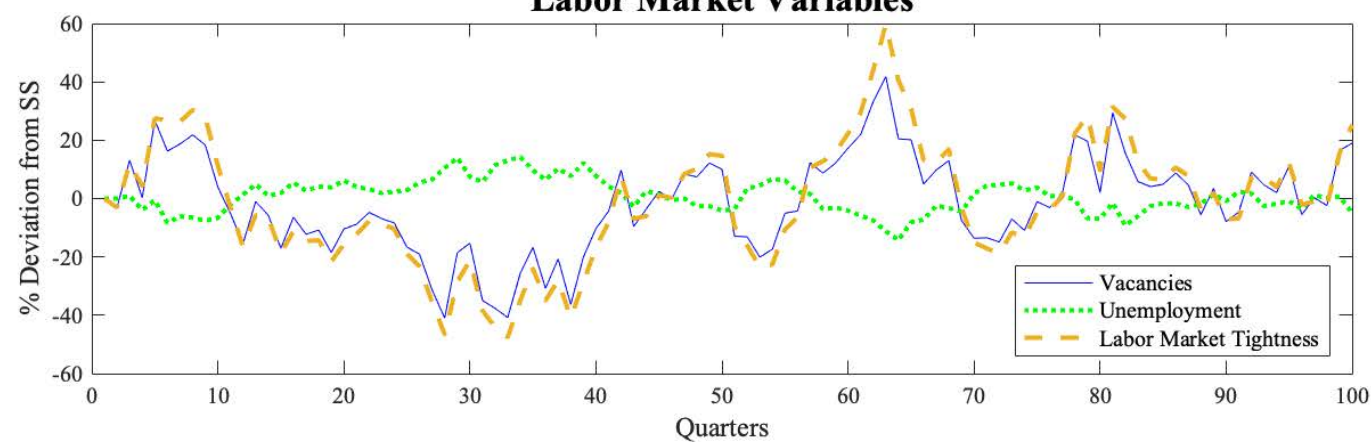

Environmental Variables

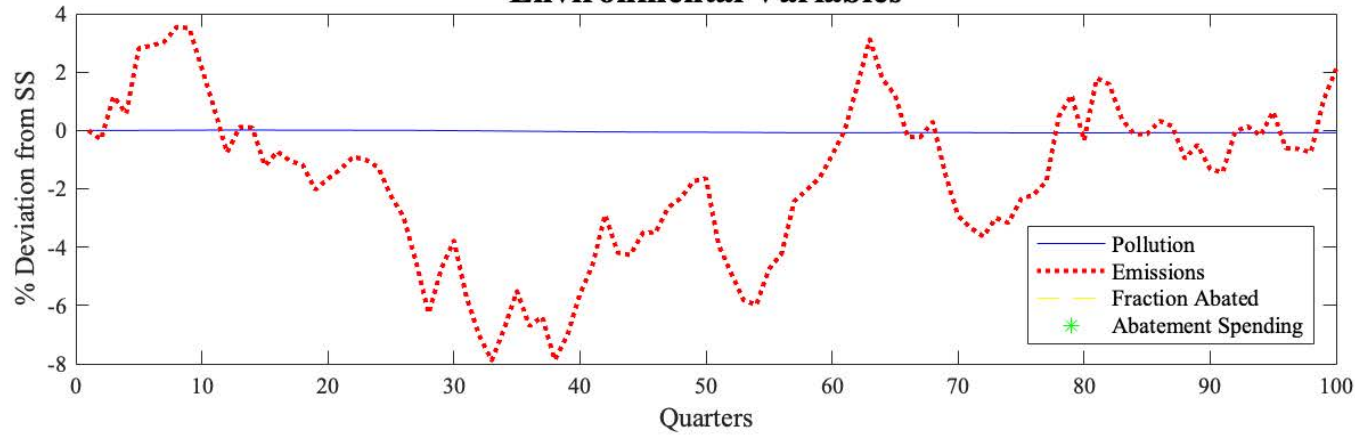

Notes: All simulations are from randomly generated draws of productivity innovations for 100 periods. 
Figure E.3: Impulse Response Functions - Planner's Problem
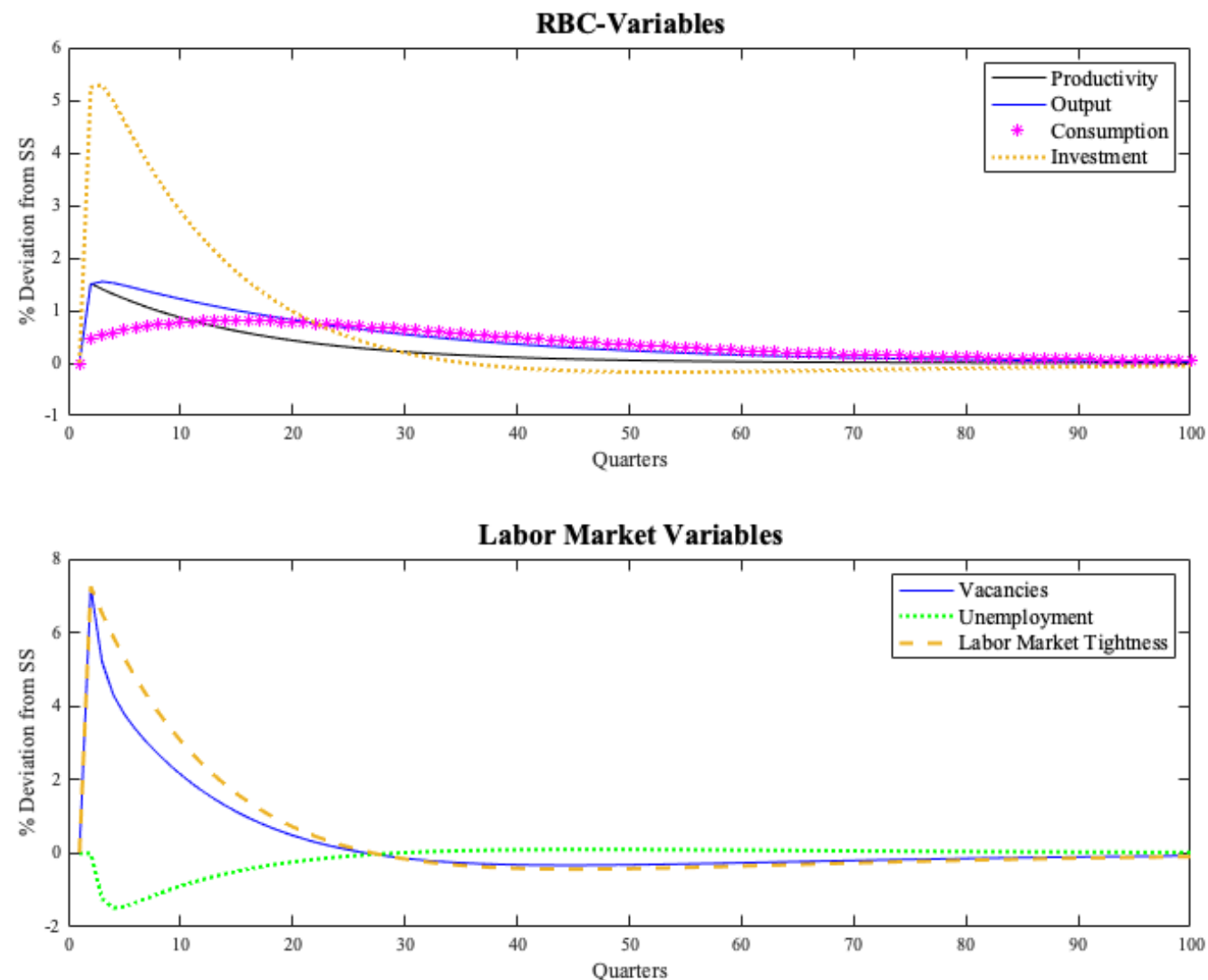

Environmental Variables

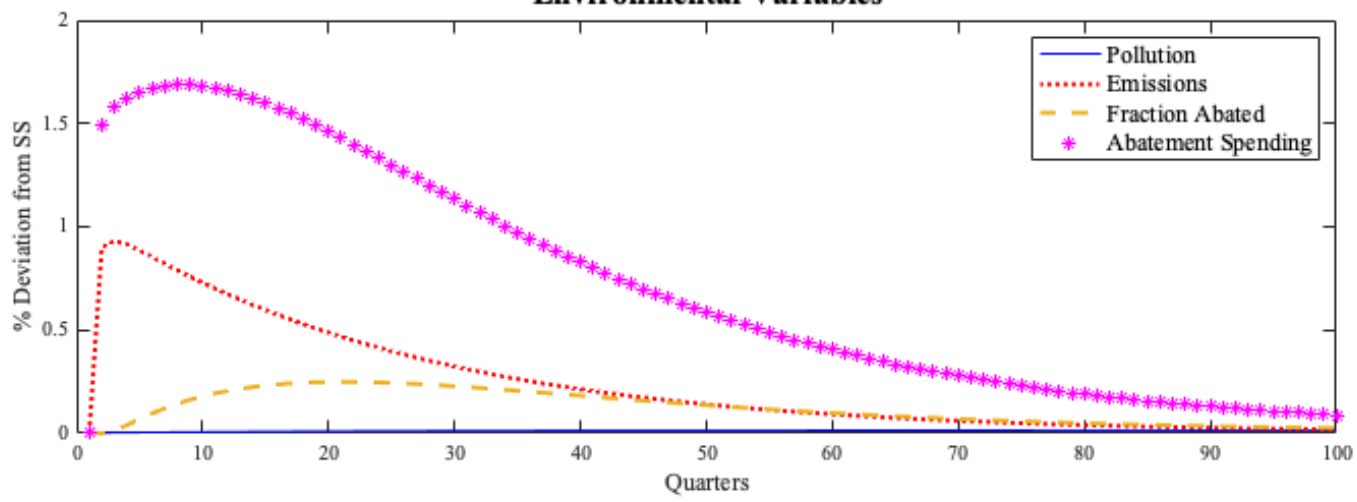

Notes: All simulations are from a one-unit one-time productivity innovation. 
Figure E.4: Business Cycle Simulations - Planner's Problem
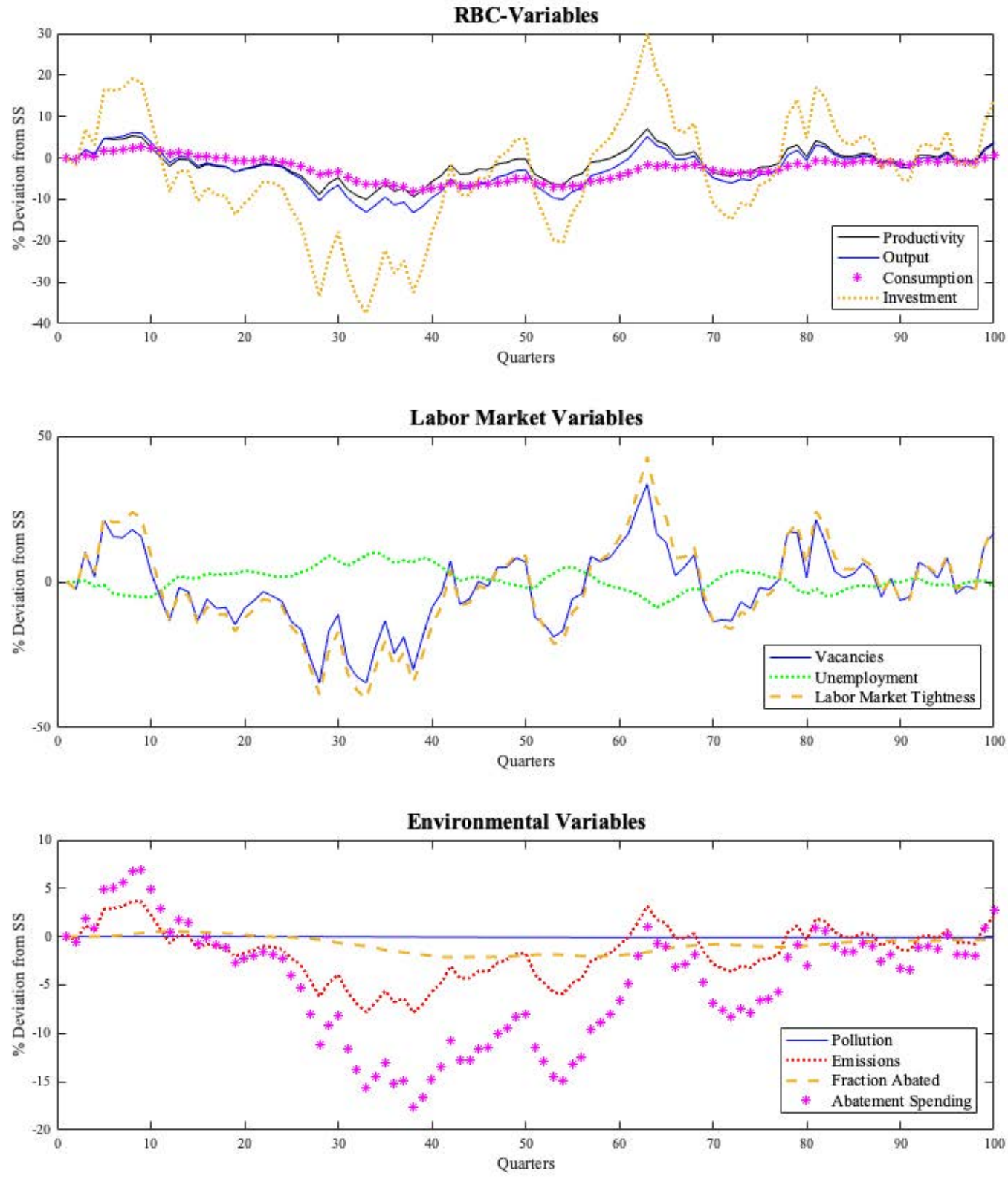

Notes: All simulations are from randomly generated draws of productivity innovations for 100 periods. 
Figure E.5: Business Cycle Simulations - First-Best Taxes
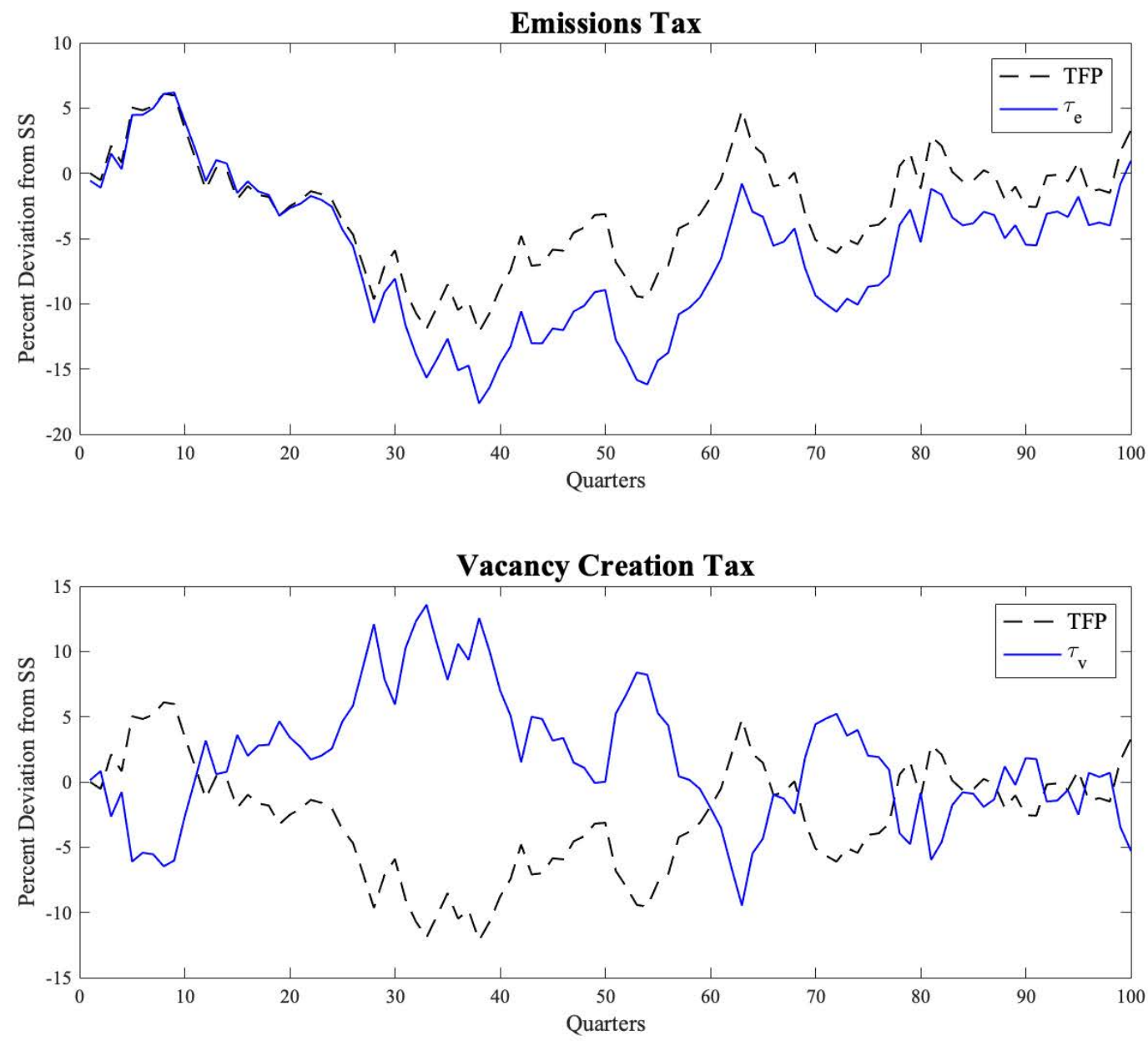

Notes: All simulations are from randomly generated draws of productivity innovations for 100 periods. 
Figure E.6: Business Cycle Simulations - First vs Second Best Taxes
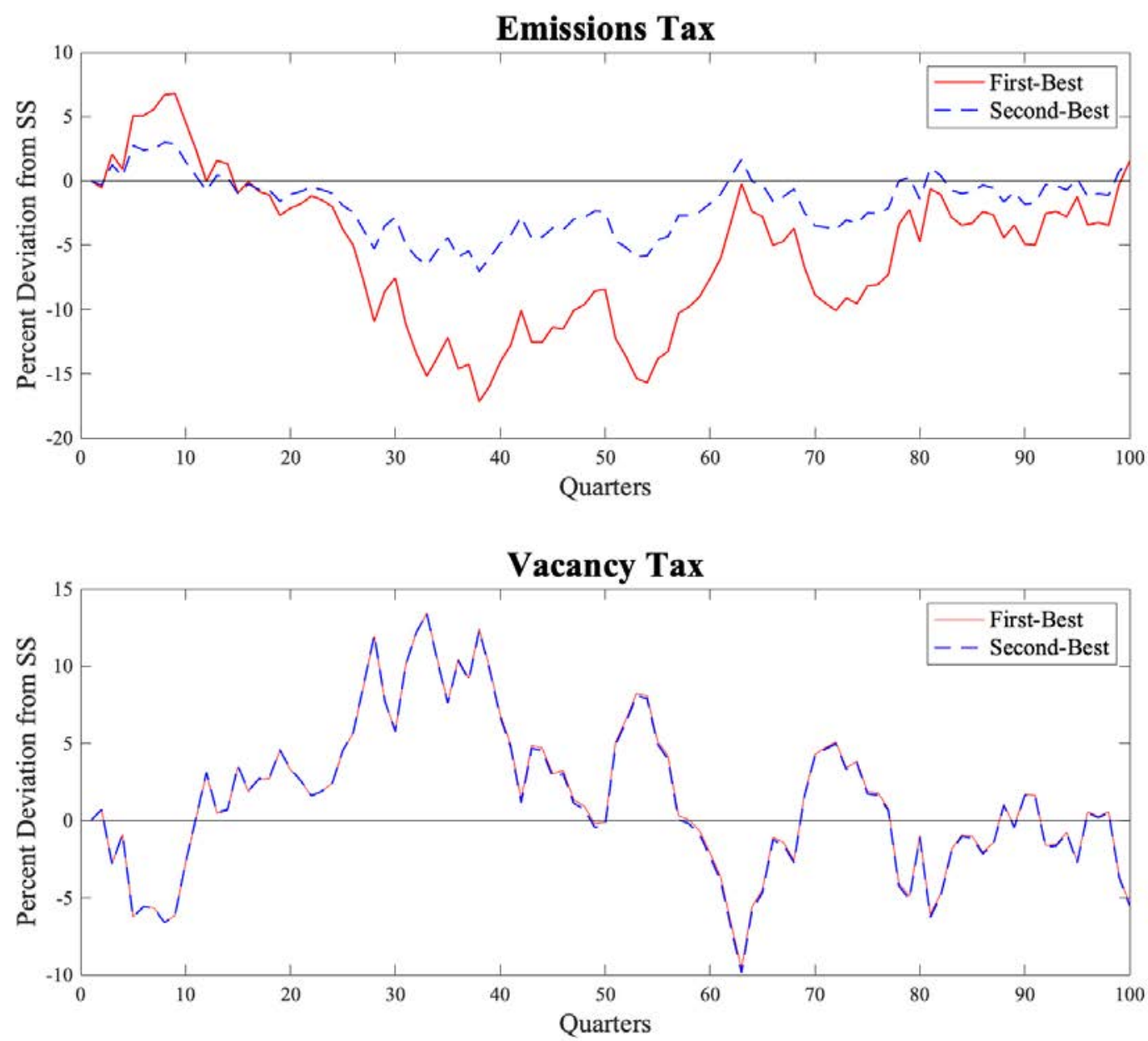

Notes: All simulations are from randomly generated draws of productivity innovations for 100 periods. 
Figure F.1: Transition Dynamics

\section{Consumption}

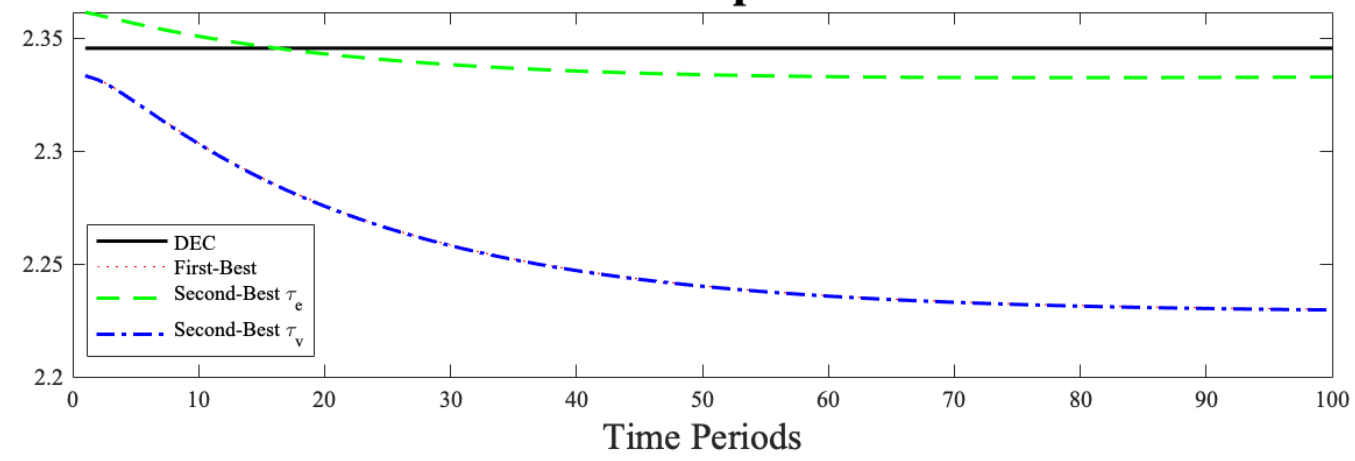

Employment

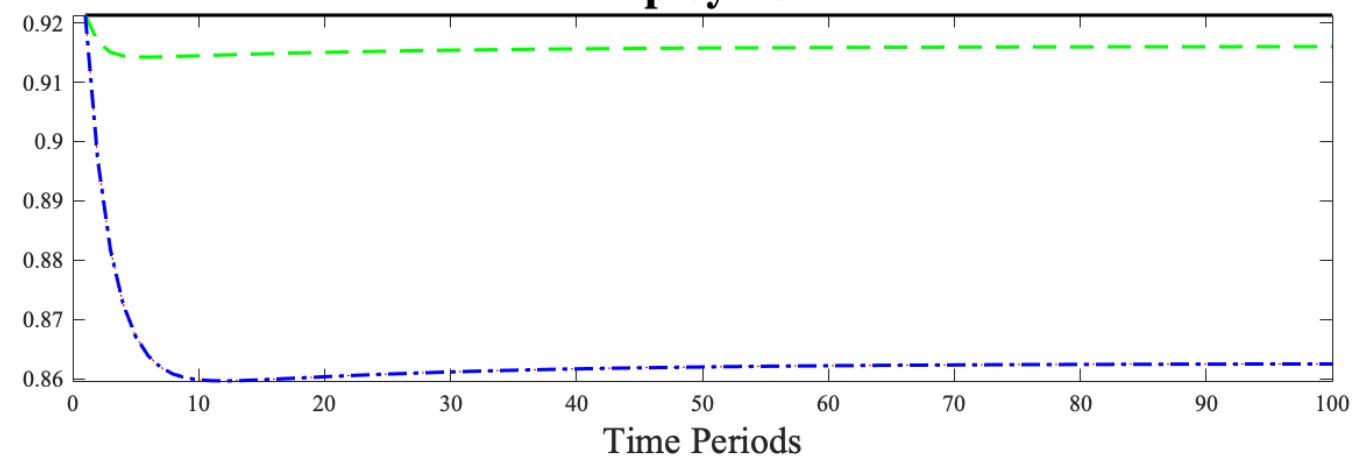

Utility

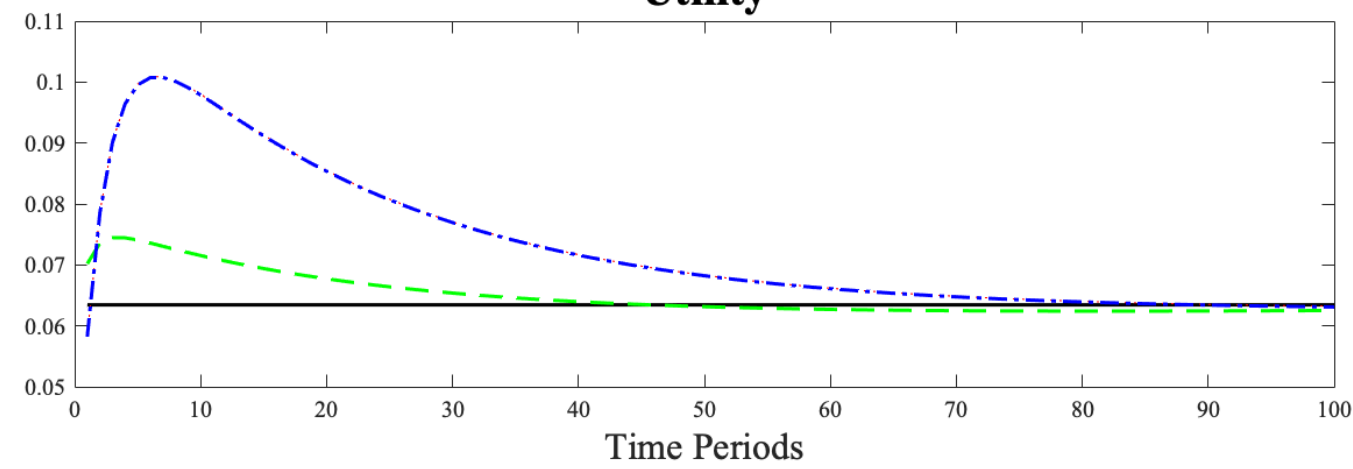

Notes: All simulations begin at the decentralized (no policy) equilibrium steady state and feature no TFP shocks. 
Figure G.1: Sensitivity Analysis - First-Best Taxes
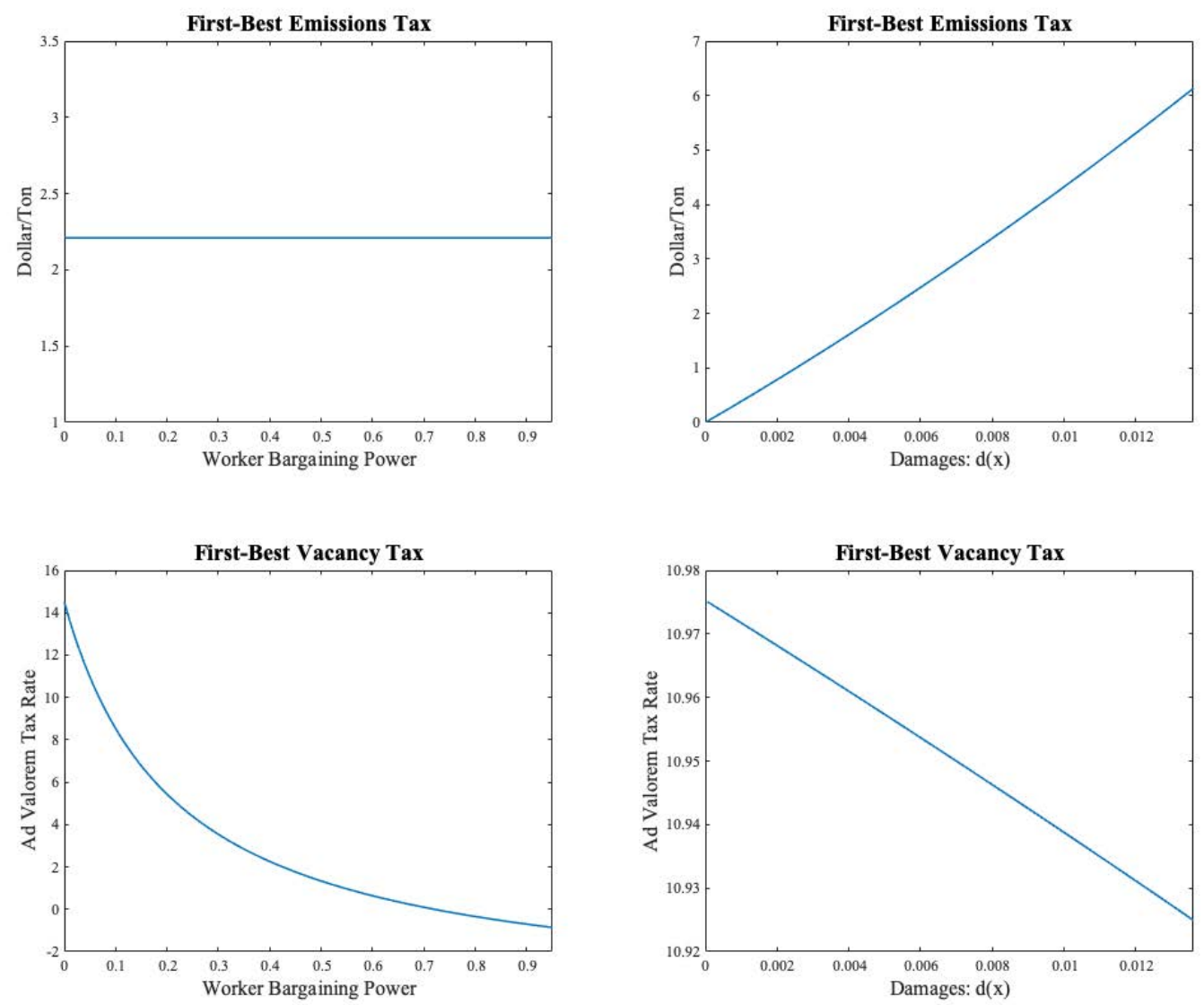

Notes: Simulations of the first-best emissions and vacancy creation taxes for different values of bargaining parameter $b$ and pollution externality. 
Figure G.2: Sensitivity Analysis - Second-Best Taxes
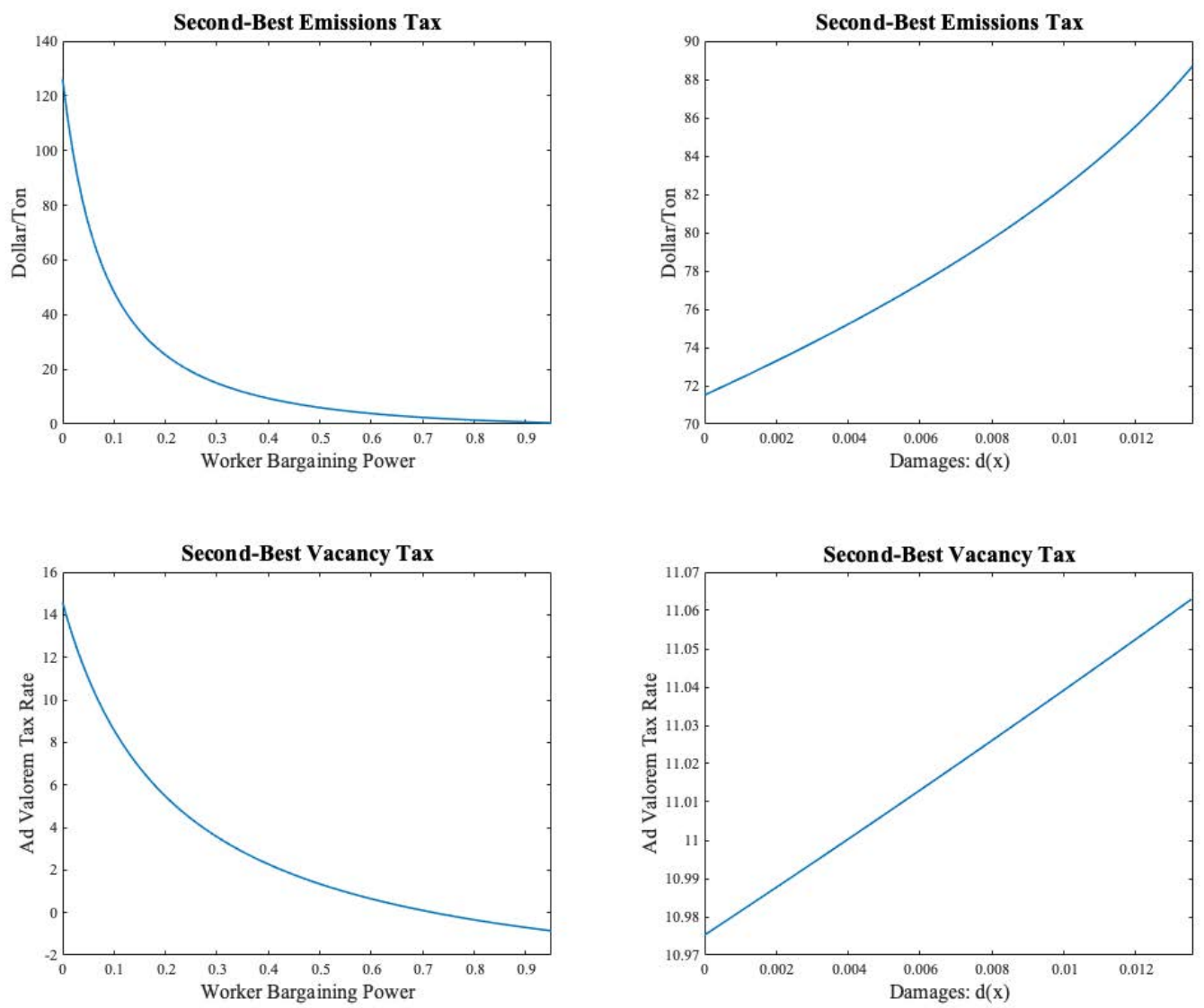

Notes: Simulations of the second-best emissions and vacancy creation taxes (when the other tax is fixed at zero) for different values of bargaining parameter $b$ and pollution externality. 
Figure H.1: Unemployment Disutility
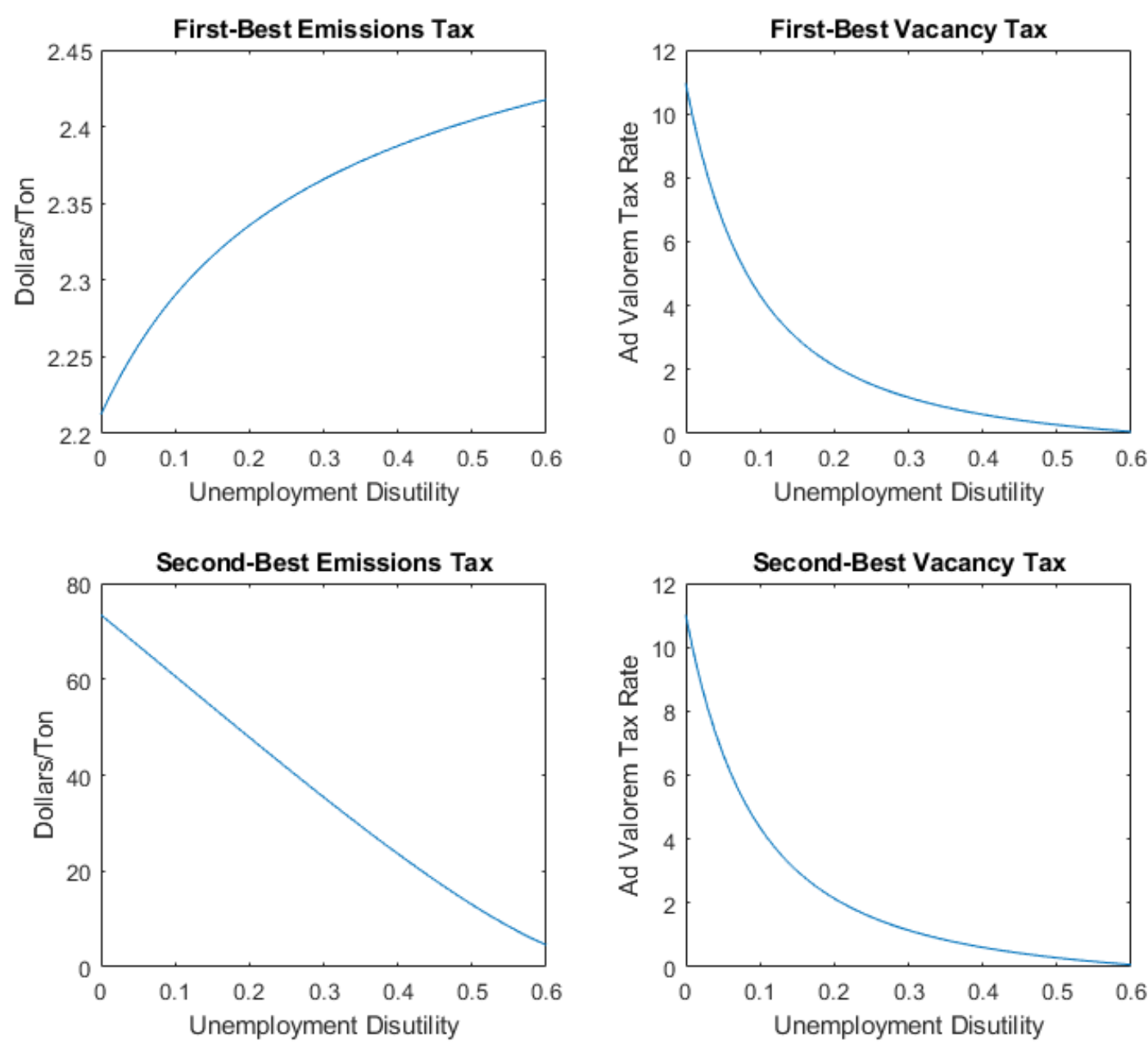

Notes: Simulations of the first- and second-best emissions and vacancy creation taxes for different values of the unemployment disutility parameter $\kappa$. 